Article

\title{
Evaluating Climate between Working Excellence and Organizational Innovation: What Comes First?
}

\author{
Isabella Bonacci, Andrea Mazzitelli and Donato Morea * \\ Faculty of Economics, Universitas Mercatorum, 00186 Rome, Italy; isabella.bonacci@unimercatorum.it (I.B.); \\ a.mazzitelli@unimercatorum.it (A.M.) \\ * Correspondence: donato.morea@unimercatorum.it
}

Received: 29 January 2020; Accepted: 17 April 2020; Published: 20 April 2020

\begin{abstract}
This research introduces a new concept of organizational climate, seen as a "mediator", namely a factor liable to produce positive effects on both individual performances and on work processes and relations, thereby creating a favorable relationship between work excellence and organizational innovation. Health systems have been called to promote sustainability, as actors who work for the health and well-being of their patients. Starting from these considerations, this work shows the main results of a longitudinal study conducted in the pediatric department of a large hospital in southern Italy, for a period of three years (May 2014-May 2017). The reference survey was very broad because in the first step of the research a general questionnaire was adopted which included various aspects. Subsequently, the analysis of the influence of the "climate" factor was carried out according to a 3-dimensional scheme: structural, interpersonal/relational and individual. The focus was therefore set—especially in the second survey—on those indicators responding to the objective of the research and that were consistent with the epistemological choice made. The main scope was to verify the conditions according to which the organizational climate can emerge as a novel factor capable of siding with and orienting innovative patient-centered policies of human resources management.
\end{abstract}

Keywords: organizational climate; healthcare organization; change management; human resources management; innovation; organizational sustainability

\section{Introduction}

Nowadays, healthcare organizations (HCOs) are forced towards a global competitiveness market, relentlessly pursuing goals of excellence and innovation that often require a deep transformation from the inside [1].

The present research tackles with both a micro (individual) and macro (system-wide) concept of innovation, in order to understand the role played by each single factor in easing or hindering the mentioned phenomena. Therefore, in coherence with this theoretical approach, three categories of factors were isolated: 1) work; 2) organizational structure; 3) organizational dynamics [2]. For this purpose, the studies conducted at an international level on the organizational climate [3,4], in a logic of organizational sustainability, along with the results provided by the authors in previous works [5], all highlighted the influence of worker-related factors on the organizational processes at any level. This work innovates the research on organizational climate by considering the latter as a determinant of both the individual behavior of employees and the global performance of the organization, i.e., a hard factor that actively contributes to shaping the organizational system, rather than a soft variable linked to organizational working dynamics.

Organizational climate embodies the "psychological atmosphere that surrounds an organization, as the result of its structural operations" [6]: it seems that the climate is at the same time the result and 
one of the main determinants of the behaviors of both individuals and groups within the organization, and assumes moreover a role of "mediator" for what concerns the productivity of the system. Such wider representation of the organizational climate depends in turn on a wider idea of the organizational system, no longer seen as a mere sum of resources aimed at achieving a goal, but rather as an "open system" permeable to the influence of the surrounding external environment [6].

Under this perspective, the organizational behavior becomes synonymous of identity, in the sense of internalizing the norms, habits and objectives of the organization: this could imply on the one hand that employees are called to act as proactive elements within a high-level subject (the organization) that strives to activate and coordinate human-based processes in order to achieve excellence; on the other hand, the management triggers processes of hiring employees and developing their knowledge and skills, so that they become more valuable to the organization (human resources management/HRM).

This study, conducted in a healthcare environment, intended to show by means of a novel approach that the correlations between the climate and performance cannot be explained only by their common dependence on HRM factors; in addition, the data that were consistent with a mediation model in which the effects of HRM practices on business performance were partially mediated by work climate.

The proposed mediation model was based on level-of-analysis interpretation of the climate as a set of convergent, level-adjusted perceptions or appraisals of relevant policies, procedures and practices as indicators of desired role behavior (i.e., climate emerges from consensual motive-relevant assessments of key features of the organizational environment, taking place in a Lewinian psychological field [7]).

A longitudinal study was conducted in the pediatric ward of a large-size hospital in the city of Naples, Campania Region, in southern Italy, over a three-year period. Activities such as interviews, focus groups and survey administrations were implemented to gather information from healthcare operators as to their perceptions and expectations regarding their working environment, and to investigate the consequences under a wide range of aspects. An action research method [8] was therefore deployed in order to evaluate the change of the working models and the patients' assistance processes, as well as the role of the organizational climate, after a deep re-organization of the entire department. The choice of the method relied upon it being considered as an effective tool to investigate the organizational change of the healthcare sector $[9,10]$. The main scope was to verify the conditions according to which the organizational climate could emerge as mediation factor capable of siding with and orienting innovative patient-centered policies of human resources management.

The work is organized as follows: after the introduction (Section 1), we present an extensive literature analysis on the concepts of organizational climate and its relations with work characteristics and organizational change (Section 2). Then, we introduce the methodological approach (Section 3) and describe the main research results (Sections 4 and 5). We conclude with a general discussion of our findings and limitations (Section 6) as well as highlight practical implications and future vistas (Section 7).

\section{Literature Review}

Several approaches to the organizational change can be recognized in the literature. It indicates by and large the perception of an (usually working) environment from the people who belong to it. Such a perception is particularly valuable in that it can affect to different extents the activities performed within the mentioned environment. The original idea of organizational climate refers in turn to the concept of group dynamics, and is based on the so-called Lewin's "field theory" (1951) that claims that human behavior can be investigated by means of the function $H=f(E$, I), i.e., the human behavior $(H)$ depends on the surrounding environment (E) as well as the individual themselves (I) along with their nature, personality and experience.

A historical overview of the various streams of research [11] made it possible to summarize the most significant aspects of the evolution of the concept of organizational climate (Table 1). 
Table 1. Analysis of the literature (source: authors' elaboration).

\begin{tabular}{clc}
\hline \multicolumn{1}{c}{ Years } & \multicolumn{1}{c}{ Organizational Characteristics } & Reference \\
\hline 1930 to 1959 & Social climate and group dynamics & {$[12]$} \\
\hline \multirow{2}{*}{1964 to 1974} & $\begin{array}{l}\text { Social variables that influence behavior; } \\
\text { Set of specific attributes of a particular organization }\end{array}$ & {$[12]$} \\
\hline \multirow{2}{*}{1975 to 1980} & $\begin{array}{l}\text { Characteristic (or attribute) of an organization thus introduced through } \\
\text { two different approaches: objective and subjective }\end{array}$ & {$[14]$} \\
\hline \multirow{2}{*}{1980 to 1986} & $\begin{array}{l}\text { It is at this stage that the first climate surveys for healthcare } \\
\text { organizations are introduced }\end{array}$ & {$[15,16]$} \\
\hline \multirow{2}{*}{1990 to $2000 \mathrm{~s}$} & $\begin{array}{l}\text { Identify four types of approaches that have characterized the climate } \\
\text { research: structural approach, perceptive approach, interactive } \\
\text { approach and cultural approach; } \\
\text { Climate, empowerment and information on organizational change are } \\
\text { factors that can significantly affect an individual's ability to effectively } \\
\text { respond to the stress generated by change; } \\
\text { The most important factor for the creation of a "good" climate is the } \\
\text { leadership inside an organization }\end{array}$ & {$[11]$} \\
\hline 2007 to 2016 & $\begin{array}{l}\text { The effects of individual behavior and culture on organizational } \\
\text { performance are mediated by the working climate }\end{array}$ & {$[11,19]$} \\
\hline 2017 to 2019 & $\begin{array}{l}\text { The organizational climate as a hard organizational variable } \\
\text { [20-30] }\end{array}$ & \\
\hline
\end{tabular}

This overview aimed to highlight how the organizational climate could be considered a tool through which the constant monitoring and improving of organizational learning is linked to a process of change. In addition, the study of the organizational climate and the resulting knowledge also represented a starting point to take action through appropriate programs and actions of (also economic) development.

Evaluating the organizational climate as a variable capable of influencing the company's performance represented the starting point of this research work. In particular, we started from the consideration that the climate can mediate between individual (micro) and organizational (macro) aspects and determine a positive impact on organizational behavior and therefore on company performance. Some research hypotheses were formulated for the analysis of the organizational climate, related to the variables measured in two different time periods: time T1 May 2014, referring to the first survey, time T2, May 2017, indicating the period of the second survey. The choice to carry out the second analysis was linked to the need to understand if the corrective interventions made at the end of the first survey produced effects.

H.1. The working excellence was based on the relation between the HRM-based variables and the organizational climate.

H.2. The relation between the working excellence and the innovative organizational performances was mediated by the organizational climate.

H.3. The relation between the innovative organizational performances and the organizational climate impacted on the quality of the healthcare delivery service.

H.4. The transformation of the working characteristics, by means of a timely commitment, resulted in a safety (organizational) climate.

\section{The Variables of the Organizational Climate}

Despite the many theories developed over time, as showed before, a sort of agreement actually existed among scholars as to the multidimensional nature of the organizational climate [31]. Figure 1 shows some of the main approaches developed in the literature that introduced the organizational 
climate as a complex phenomenon involving on the one hand a plurality of forces and on the other hand a plurality of outcomes (work effects) [11,19].

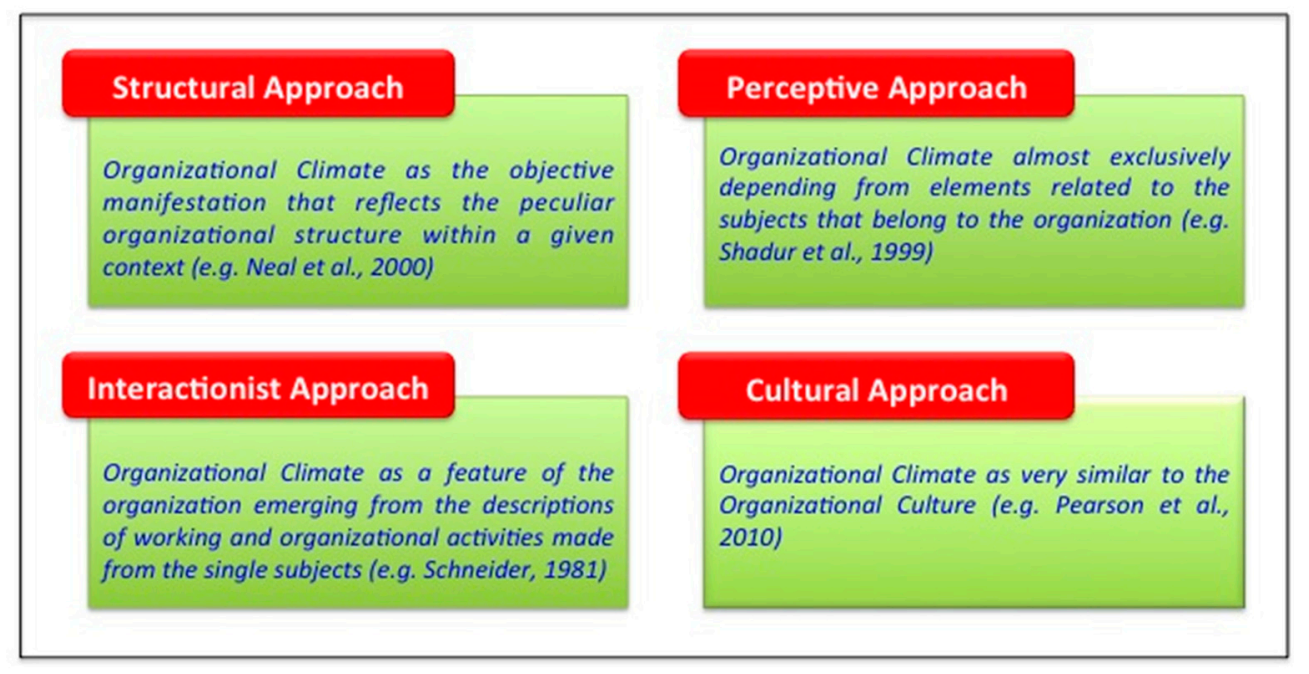

Figure 1. Different approaches to the organizational climate (source: authors' elaboration).

Some of the most important variables, both internal and external, that influenced the climate are HRM-based: the importance of the human resources management feature was explained in that in order to get to an improvement of the climate, and achieve accordingly a positive impact on the performance, it is crucial to enhance the ways in which employees work [32]: this can be summarized stating that the "work excellence" is influenced by the "work climate". As a consequence, a non-timely acknowledged and handled organizational climate can reveal as an obstacle to productivity and thus to the attainment of the preset goals [18].

Huselid [33] found that HRM practices such as employee recruitment and selection procedures, compensation and performance management systems, employee involvement employee training significantly impacted on employee turnover and productivity and, in the middle-long term, on corporate financial performance.

Over one hundred different HRM-related features were detected in the literature, whose meanings partially (and sometimes completely) overlapped. Morgeson and Humphrey [34] narrowed their number down to 18 and summarized them in turn into three macro categories, namely: motivational, social, and environment work features (Table A1, in Appendix A).

A second round of literature analysis was then performed to highlight the role and the influence of the work characteristics in the processes of organizational change. The result was an organizational climate questionnaire (OCQ) [34] based on the work design questionnaire (WDQ) guidelines. In particular, one of the main criteria adopted for the analysis was to point out that the concept of excellence for an organization not only refers to the high and positive performance levels achieved, but also to whether its workers recognize themselves in such achievements. The work-related variables identified therefore mostly belong to the motivational sphere as, on the one hand, they meaningfully convey the overarching complexity of the "work" concept and on the other hand, they have the greatest impact on the processes of organizational change in the selected studies, so they were considered in the present work as extremely valuable for the evaluation of the organizational climate as well.

\section{Materials and Methods}

The empirical analysis was performed following the action research method (ARM) [10], an approach commonly used for improving the conditions and practices in a wide range of healthcare environments [35]. 
The ARM comprises four main phases, i.e., diagnosing, planning, acting and evaluating [36]. These phases recur cyclically, starting from the definition of a general idea or the identification of a problem at both the theoretical and practical level and concluding when the idea or problem is fixed. The ARM recognizes that a research project should result in two outcomes, namely an action outcome and a research outcome. The first means the practical learning in the research situation, and helps understand the extent to which the organization benefits in addressing its original problem. The second is instead very much concerned with the implications for the advancement of theoretical knowledge resulting from the project [37].

The use of the ARM methodology for investigating organizational climate seemed to be particularly appropriate for several reasons. Firstly, as seen in the literature analysis, scholars stressed a lot on the organizational climate being strongly affected by the context, thus any research investigating the subject must take into account the organizational context. To this purpose, a fundamental characteristic of the ARM is to use the organization as a physical laboratory for developing and testing practical interventions and advancing knowledge closely related to the context. Secondly, the "research in action" deals well with the outstanding need of improving knowledge about how organizations can assess and manage the organizational climate for enhancing the value created for stakeholders, since it allows to extract from practice, in accordance with an inductive approach, insights to be combined with those based on a theoretical deductive approach. The present study reported the results of the diagnosing and planning phases of the ARM involving the processes of data collection, data analysis, planning and validating the evidence and critical reflection, before applying the findings to improve the practice or effectiveness of the working system. This is a preliminary phase, before the acting phase (currently ongoing) and the evaluation of the whole process, in terms of the impact on business performance; both of these two last phases were not analyzed in the present work.

The research activity was performed in the pediatric ward of a large-size hospital of national relevance (according to the Italian legislation, a "hospital of national relevance" is a particular healthcare organization that delivers highly specialized healthcare performances thanks to advanced diagnostic-therapeutic equipment, and whose mission is directly defined by the Regional Healthcare Planning policy) in the city of Naples, Campania Region, southern Italy, over a 3-year period, from 1 May 2014 to 1 May 2017.

The research focused on the conversion of the original single pediatric ward into a two level II operative units coordinated by a supervising level I operative unit, with a general increase of $15 \%$ of the total beds available and of $20 \%$ of the cradles in the nursery. No variation occurred for the workforce (nurses). A longitudinal analysis by means of an action research method (ARM) [10] approach was then implemented, using both qualitative and quantitative methods. In particular:

- quantitative methods: two questionnaires built on the basis of validated scales $[38,39]$ were administered to the healthcare operators at the beginning and at the end of the research period;

- qualitative methods: semi-structured interviews, focus groups, regular meetings with the hospital's healthcare (HC) quality manager, and field observations of employees' work were implemented.

Table A2 (in Appendix A) points out which among the HRM-based variables observed in the study and whose influence on the features of the organizational climate were investigated, were considered at the beginning (T1) and at the end (T2) of the study. The reasons of this choice will be made clear in the following paragraphs. Figure 2 describes the development of the main phases of the process, highlighting the connections between the main organizational dimensions analyzed during the ward re-organization and the actions performed to involve and support the personnel. In particular, a first phase was focused on the evaluation of the quality of the working life of the healthcare operators (especially nurses) involved in the process. To this purpose, a first questionnaire was administered and then focus groups with the nurses on the one hand and interviews with the coordinators of the process on the other hand were carried out to evaluate the two complementary sides of the same phenomenon, i.e., the disruption of the pre-existing organizational routines. 


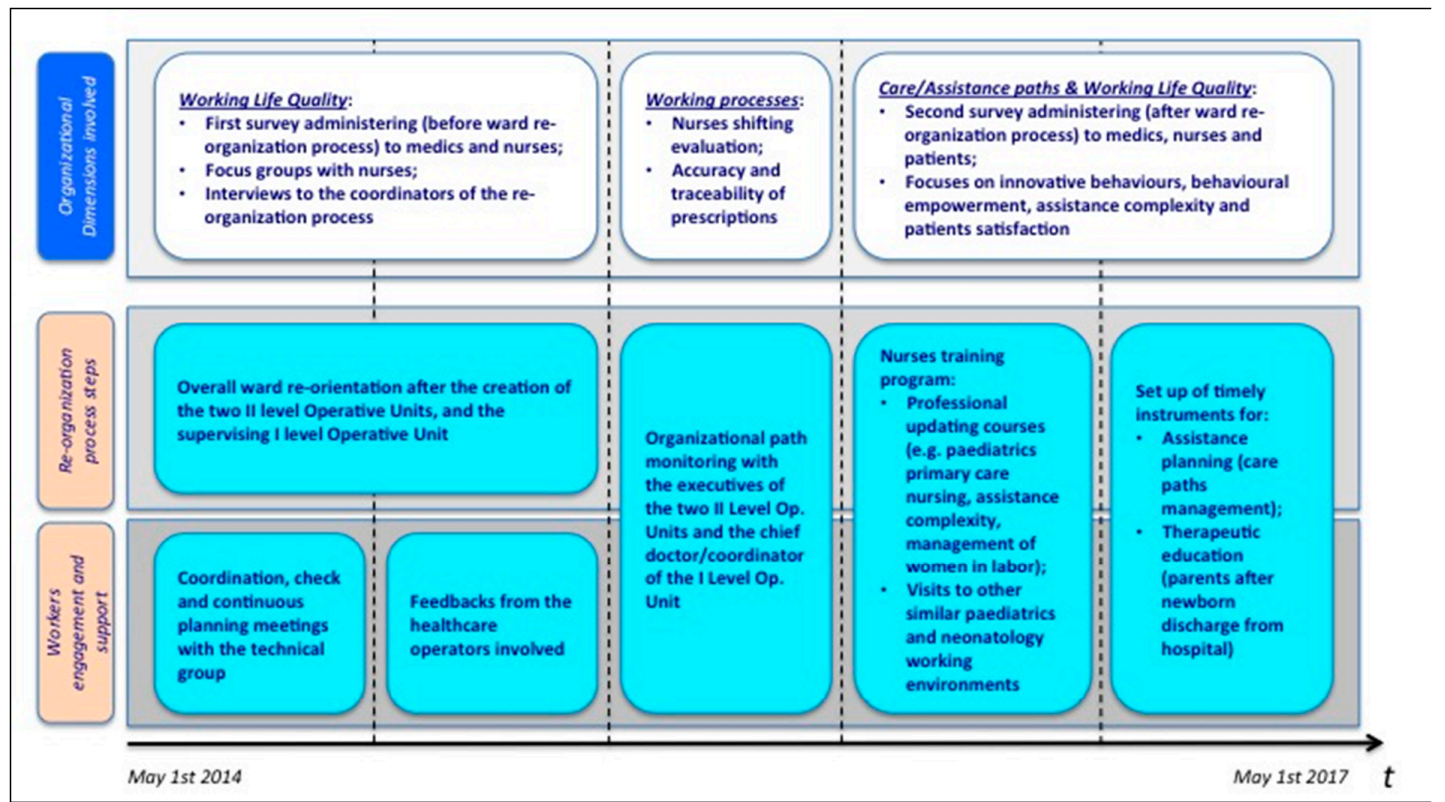

Figure 2. Main steps of the re-organizational process (source: authors' elaboration).

A second step was devoted to the monitoring of the creation and deployment of the new organizational paths, as the new structure was being initialized, with a specific focus on the new shifting dynamics for nurses.

In the last phase a second questionnaire was administered in order to finalize the comprehension of the role of the organizational climate capable of, under an HRM-based perspective, playing the role of a mediator affecting the relation between working excellence and organizational innovation. To this end, the patient-related perspective was then mainly taken into account as evidence of the positive outcome of the entire process of (not only structural) change.

The research process featured a three-fold aim:

- to analyze the rate of the adaptation of the workforce to the changes that occurred, pointing out the eventual capacity of the operators involved to keep pursuing high performance results (working excellence);

- to support the organization in achieving, as the primary objective, the creation of a base of useful information for planning and steering actions and processes of positively perceived change, meant to promote the spread of quality services in the outside territory (organizational innovation);

- to improve the theoretical framework of the organizational climate in a highly knowledge-intensive organization (the hospital), with the support of empirical evidence and knowledge, and specifically to highlight its role in allowing the accomplishment of the first two points.

Some research hypotheses were therefore formulated for the analysis of the organizational climate, related to the variables measured at $\mathrm{T} 1$ and $\mathrm{T} 2$.

H.1a. The working excellence was based on the relation between the HRM-based variables and the organizational climate.

H.2a. The relation between the working excellence and the innovative organizational performances was mediated by the organizational climate.

H.3a. The relation between the innovative organizational performances and the organizational climate impacted on the quality of the healthcare delivery service.

H.4a. The transformation of the working characteristics, by means of a timely commitment, resulted in a safety (organizational) climate. 
The four hypotheses were verified through the application of different statistical methods, among which a regression and correlation analysis and a preliminary causal mediation analysis. The aim of the mediation analysis was to identify and evaluate the mechanism through which a treatment affected an outcome [40], i.e., the relation between the working excellence and the organizational innovation. Its goal was to disentangle the total treatment effect into two components: the indirect effect that operated through one or more intermediate variables called mediators (organizational climate), and the direct effect that captured all other possible explanations for why a treatment works. The mediator (M) lies in the causal pathway between the treatment and the outcome $(\mathrm{Y})$ and may be correlated with different observable covariates. Causal mediation analysis had important implications, because it allowed to optimize decisions, making them more efficient. In our analysis, we wanted to verify if the organizational climate can be assumed as a mediator in the innovation process, and which were the predictive independent variables $(X)$ that affected the mediator (Figure 3 ).

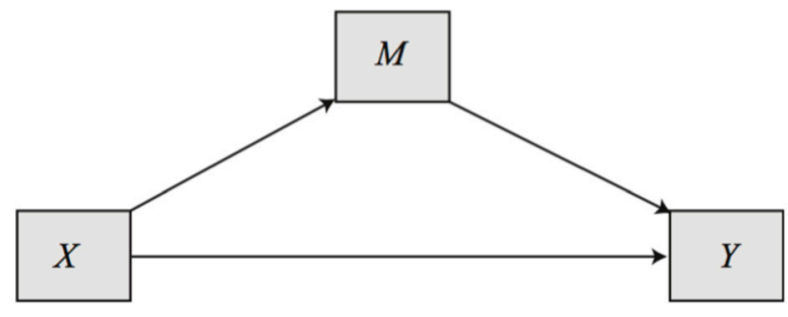

Figure 3. A simple mediation model [41].

Regression and correlation methods can be used as a preliminary exploratory analysis in the identification of the causal relationship between the $X$ and $M$ variables. The complete mediation mechanism could only be applied after the acting phase, that was able to evaluate the whole process, through the observation of the outcome $\mathrm{Y}$.

\section{Survey Administering}

As mentioned in the previous section, the organizational climate questionnaire (OCQ) introduced by Litwin and Stringer [42] was used as a proper WDQ in order to investigate the relations between the organizational context and the ways it was perceived by the members of the organization. The organizational climate was accordingly described as the synthesis of the total perceptions of the workers [43]. The OCQ comprised 50 items for which the answer had to be expressed from a 54-points Likert scale spanning from "completely agree" (score 54) to "completely disagree" (score 1). The questionnaire was built in order to gather information as to:

- Structure: the workers' experience in relation to the methods, rules and organizational routines;

- Responsibility: whether workers felt to be the bosses of themselves;

- Prizes: the presence or not of rewards;

- Risk: the sense of risk and challenge in the work as well as in the organization;

- Support: the perception of receiving help from managers and other workers;

- Warmth: the perception of cohesion and trust within the working environment;

- Standards: the perception of the importance of both implicit and explicit results.

Two survey questionnaires were administered in two different moments: the first one (May 2014) before starting the re-organizational process (T1), was aimed at investigating the perception of the healthcare operators involved (doctors, nurses, socio-sanitary workers) as to some individual and collective psychosocial factors. The second one (May, 2017) at the end of the process (T2) was aimed at evaluating the impact of the change.

The first part of the questionnaire referred to registry- and work-related data, e.g., age, gender and education degree, plus information concerning the professional role, e.g., the duration of working 
shifts, years of work and eventual transfer requests to other wards/hospitals. The second part was mainly focused on the variables to be analyzed in the study.

Both questionnaires were administered to all kinds of workers of the interested units, in particular: 4 to administrative workers, 56 to doctors, 100 to nurses and 20 to social workers, for a total of 180 people (population of the study).

In both cases the population was then divided into: three classes of age ( $\leq 32$ years, 33-44 years, $\geq 45$ years); three classes of general work seniority ( $\leq 5$ years, $6-14$ years, $\geq 15$ years); three classes of work seniority for the specific ward ( $\leq 3$ years, $4-15$ years, $\geq 16$ years).

At $\mathrm{T} 1$ the return rate was $84.9 \%(\mathrm{n}=153)$, i.e., $100 \%$ from administrative and social workers, $93.4 \%$ from nurses and only $50 \%$ from doctors. All the questionnaires received were considered valid. The mean age of the respondents was 39.49 years ( $S D=10.42$ years). Their average work history was of 12.81 years ( $\mathrm{SD}=10.2$ years) and more specifically of 10.23 years $(\mathrm{SD}=9.73$ years) in the pediatric ward.

The population was mainly composed of young (about $66 \%$ was younger than 44 years of age) and female people (about $75 \%$ ). For professional seniority, $36.6 \%$ exceeded 15 years, while $25.4 \%$ of the interviewees had worked in the pediatric ward for more than 16 years.

At $\mathrm{T} 2$ the return rate was the $64 \%(\mathrm{n}=115)$, i.e., $100 \%$ from administrative, $76.5 \%$ from social workers, $76.1 \%$ from nurses and only $34.6 \%$ from doctors. All the questionnaires received were considered valid. The mean age of the respondents was 40.23 years (SD $=9.82$ years). Their average work history was of 14.07 years ( $\mathrm{SD}=9.60$ years) and more specifically of 9.63 years ( $\mathrm{SD}=8.40$ years) in the pediatric ward.

In this case the population was also mainly composed of young (about $62.5 \%$ was younger than 44 years of age) and female people (about $75 \%$ ). For professional seniority, $46.4 \%$ exceeded 15 years, while $19.6 \%$ of the interviewees had worked in the pediatric ward from more than 16 years.

\section{First Survey Results (T1)}

Our hypothesized mediation model was analyzed and estimated through ordinary least squares path analysis following Hayes [41] in SPSS 21.0. software, where a set of linear regression models were fitted to define the causal relationships at the basis of the mediation process. These relationships could be used to estimate the "mediation effects" of the fitted models. The procedure implemented by Hayes through the macro process enabled the computation of the mediation effects and their confidence intervals, through the application of a bootstrap procedure, which resampled the data multiple times (5000 times in our study, as per Hayes' [41] recommendations). Following Hayes, the causal mediation analysis was based on the correlation between the variables. Longitudinal data, as those observed in our study, offered an advantage in establishing a causal association, because the temporal ordering may have helped to define the direction of the cause. However, the mediation analysis was not properly the same as the causality analysis, as highlighted by Hayes himself [41], but rather a " ... product of our minds: how we interpret the associations we have observed, the signal we believe we have extracted from the noise.". However, in this phase of the ARM process of data collection, data analysis and planning, the mediation analysis was made using the correlation and the regression analysis as appropriate instruments, because in this preliminary study phase, we needed first of all to identify the causal relationships at the basis of the mediation model.

Before performing our empirical analysis, the normality of all the covariates was verified through the Jarque-Bera test: normality was accepted in all cases, with all p-values greater than 0.05 . Furthermore, the assumption of the linearity in the relationship between the variables was made.

\subsection{Descriptive Analysis}

In the first phase of data analysis, the average value and standard deviation for all the variables studied were calculated. The same was done (where possible) with the Cronbach Alpha as an indicator of internal consistency on a scale going from one (completely disagree) to 54 (completely agree). The most significant statistical data were reported in Table 2. The Cronbach Alpha coefficient was used 
to validate the reliability of the proposed Likert scale, where values greater than 0.7 were considered acceptable for internal consistency.

Table 2. Main results from the descriptive analysis at T1 (source: authors' elaboration).

\begin{tabular}{|c|c|c|c|c|}
\hline Variable & Dimension & $\begin{array}{l}\text { Mean } \\
\text { Value }\end{array}$ & SD & $\begin{array}{l}\text { Cronbach } \\
\text { Alpha }\end{array}$ \\
\hline \multirow{5}{*}{$\begin{array}{l}\text { Characteristics of } \\
\text { work }\end{array}$} & Autonomous work scheduling & 2.73 & 0.83 & 0.75 \\
\hline & Autonomous choice of the work method & 3.2 & 0.75 & 0.81 \\
\hline & Autonomous decision making & 3.00 & 0.84 & 0.87 \\
\hline & Variety of the task & 3.99 & 0.76 & 0.91 \\
\hline & Identity of the task & 3.11 & 0.85 & 0.86 \\
\hline $\begin{array}{l}\text { Working } \\
\text { satisfaction }\end{array}$ & Positive emotions & 2.87 & 0.69 & N/A \\
\hline \multirow{3}{*}{$\begin{array}{l}\text { Quality of clinical } \\
\text { practice }\end{array}$} & Quality of assistance & 2.78 & 0.40 & 0.76 \\
\hline & Suitability of assistance & 2.38 & 0.74 & 0.79 \\
\hline & Collaboration between doctors and nurses & 2.72 & 0.85 & 0.84 \\
\hline $\begin{array}{l}\text { Relationship with } \\
\text { the patient }\end{array}$ & $\begin{array}{l}\text { Participation of the patient in the } \\
\text { therapeutic process }\end{array}$ & 4.05 & 0.79 & N/A \\
\hline \multirow{3}{*}{$\begin{array}{l}\text { Organizational } \\
\text { commitment }\end{array}$} & Emotional commitment & 3.09 & 0.81 & 0.81 \\
\hline & Moral commitment & 2.18 & 0.73 & 0.75 \\
\hline & Normative commitment & 2.15 & 0.77 & 0.80 \\
\hline \multirow{2}{*}{$\begin{array}{c}\text { Perceived } \\
\text { organizational }\end{array}$} & Of the organization & 2.69 & 0.81 & 0.86 \\
\hline & Of the coordinator towards the change & 3.76 & 0.83 & 0.74 \\
\hline $\begin{array}{l}\text { Support } \\
\text { Quality of } \\
\text { communication }\end{array}$ & Safe working & 2.54 & 0.88 & 0.89 \\
\hline \multirow{3}{*}{$\begin{array}{l}\text { Intention of } \\
\text { turnover }\end{array}$} & Inside the ward & 2.08 & 1.29 & N/A \\
\hline & Inside the organization & 1.55 & 1.01 & $\mathrm{~N} / \mathrm{A}$ \\
\hline & Professional & 1.25 & 0.89 & N/A \\
\hline $\begin{array}{l}\text { Working } \\
\text { uncertainty }\end{array}$ & Job satisfaction for temporary work & 1.95 & 0.53 & 0.66 \\
\hline \multirow{2}{*}{$\begin{array}{l}\text { Expectations of } \\
\text { result }\end{array}$} & Related to individual benefits & 2.98 & 0.77 & 0.87 \\
\hline & Related to organizational benefits & 2.86 & 0.95 & 0.93 \\
\hline \multirow{6}{*}{ Concerns } & As to the content of change & 1.71 & 0.57 & 0.76 \\
\hline & $\begin{array}{l}\text { As to the change management modalities } \\
\text { adopted }\end{array}$ & 2.49 & 0.86 & 0.85 \\
\hline & As to handling the change & 2.36 & 0.90 & 0.88 \\
\hline & $\begin{array}{c}\text { As to the individual capacity to cope with } \\
\text { the change }\end{array}$ & 1.69 & 0.63 & 0.80 \\
\hline & As to being left alone during the change & 2.31 & 0.64 & 0.67 \\
\hline & For the future & 2.85 & 0.78 & 0.60 \\
\hline Practical help & Re-organization dynamics & 3.67 & 0.69 & 0.91 \\
\hline $\begin{array}{l}\text { Commitment to } \\
\text { change }\end{array}$ & Commitment of the operators & 2.78 & 0.59 & 0.66 \\
\hline
\end{tabular}

From Table 2, variables can be split into different groups, depending on whether their mean is greater than three, considered as the cut-off of the agreement, or less than two (as evidence of disagreement). Variability in the responses remained almost constant over the different dimensions, except for the intention of turnover, where SD was maximum, highlighting the discordant answers of the respondents and on the other side for "quality of assistance" that showed high homogeneity.

In the first group, we found: the autonomous choice of the work method, the autonomous choice of the work method, the variety of the task, the identity of the task, the participation of the patient in the therapeutic process, the emotional commitment, the perceived support of the coordinator towards 
the change and the re-organization dynamics. The "characteristics of the work" recorded the higher positive responses, confirming its importance in the perception of the healthcare operators involved in the survey.

Moreover, the healthcare operators felt that they had a good and very satisfying relationship with the patients. Apart from that, they felt "emotionally connected" to their work environment and tended to remain there because they wanted to. They also felt a good support from the change coordinator. All this translated into a general low intention of leaving the work environment or, in general, the healthcare organization or the profession (the higher value recorded for the intention of turnover was related to the ward). It also translated into a low uncertainty at work, as well as a low concern as to possible future variations of the workload. They were eventually not very concerned with the idea of performing their job with different co-workers.

The worst results (second group) included variables like the turnover, job satisfaction, concern to the content of change and the capacity to cope with the change. These outputs can be read as the of the management inadequately informing the healthcare operators about the reasons behind the re-organization process and the possible consequences on the working dynamics. The survey also revealed the perception of a management purposely unwilling to share its point of view with the workers.

Overall, the healthcare operators involved seemed on the one hand not to have general high expectations as to the possible benefits coming with the re-organization of the pediatric ward on a personal level (e.g., professional growth) or on the organizational level (better cooperation rate between the surgical operative units, better quality of work). They were generally concerned about their future, especially in terms of how to perform their usual work, as well as about the ways through which the change management was implemented. A particular concern was about the incapacity to understand the extent of the change, and therefore to work a lot in exchange of a few actual advantages.

On the other hand, in order to facilitate the re-organization, healthcare operators deemed as a priority to be involved in decision-making processes, to have their efforts acknowledged by the management, to get feedback for their doubts, to have adequate times and spaces to become informed as to the advancement of the entire process. They eventually strongly believed in the intrinsic value of change, so they were accordingly willing to embrace such change and commit to get to the final goal.

\subsection{Correlation Regression and Mediation Analysis at T1}

The correlation and regression analysis, together with the causal analysis, was applied to the data observed in $\mathrm{T} 1$ to support the four research questions proposed in the paper.

To test the possibility that the observed relationships between the climate and the performance were due to the common influence of HRM decisions (H1), the correlations between the general climate (dependent variable) and each of the performance outcomes (independent variables) were computed. The relations between the variables was conducted through the Pearson correlation coefficients (PCC) (Table A3, in Appendix A). Table 3 summarizes the most significant results of the correlation analysis.

These correlations guided the choice of the predictor to include in the next regression. The identification of the correct relationship between the general climate (dependent variable) and each of the performance outcomes (independent variables) was made through linear regressions using a stepwise method [44], where each predictor was included one by one, until the best regression output was obtained and used in order to verify the hypothesis of the relation between the variables investigated at $\mathrm{T} 1$.

At the first step, the correlations between the variables were analyzed as a preliminary identification of possible predictors. At a second step, the regression analysis was applied by the stepwise method, reporting the standard statistics that supported the estimation, together to the rate of mediation, that showed the importance of the mediation variable in the analysis. The regressions were made sequentially, from H.1 to H.4, where each dependent variable in the regression was used to verify the next hypothesis through a causality path. 
Table 3. Correlation analysis (source: authors' elaboration).

\begin{tabular}{lc}
\hline \multicolumn{1}{c}{ Variables } & Correlation Coefficient r \\
\hline \multicolumn{2}{c}{ Correlation of “Perceived Organizational Support” with: } \\
\hline - Variety of the task (work characteristics) & +0.350 \\
- Identity of the task (work characteristics) & +0.286 \\
- Working satisfaction & +0.362 \\
- Quality of assistance (quality of the clinical practice) & +0.356 \\
- Suitability of assistance (quality of the clinical practice) & +0.530 \\
- Collaboration between doctors and nurses (quality of the clinical practice) & +0.506 \\
- Emotional commitment (organizational commitment) & +0.428 \\
- Normative commitment (organizational commitment) & +0.341 \\
- Quality of communication $\quad+0.477$ \\
\hline \multicolumn{2}{c}{ Correlation of “Concerns” with: } \\
\hline - Suitability of assistance (quality of the clinical practice) & -0.410 \\
- Collaboration between doctors and nurses (quality of the clinical practice) & -0.477 \\
- Support of the coordinator towards the change (perceived organizational support) & -0.262 \\
\hline
\end{tabular}

The stepwise regression was used to provide a screening of the candidate variables to include as explanatories in the regression. At each step, the variable with higher correlation was selected and set in the regression, and variables stopped being added when none of the remaining were significant. This procedure was a way to handle the problem of omitted variables in the final regression.

H.1b. The working excellence was based on the relation between the HRM-based variables and the organizational climate.

Table 4 shows to a different extent the influence of two dimensions of the variable "perceived organizational support" (predictors) on the quality of assistance, which is one of the dimensions of the variable "quality of clinical practice", one of the most important indicators of the work excellence.

Table 4. Regression analysis for the dependent variable "quality of assistance" (pt. II) (source: authors' elaboration).

\begin{tabular}{|c|c|c|c|c|c|c|c|}
\hline $\begin{array}{l}\text { Dependent } \\
\text { Variables }\end{array}$ & Explanatory Variables & $\beta$ & $t$-Test & $p$-Value & $\mathbf{R}^{2}$ & $F$-Test & $p$-Value \\
\hline \multirow{2}{*}{$\begin{array}{l}\text { Quality of } \\
\text { assistance }\end{array}$} & $\begin{array}{l}\text { (Perceived organizational } \\
\text { support) of the organization }\end{array}$ & 0.482 & 4.980 & 0.001 & \multirow[t]{2}{*}{0.345} & \multirow[t]{2}{*}{19.923} & \multirow[t]{2}{*}{0.000} \\
\hline & $\begin{array}{l}\text { (Perceived organizational } \\
\text { support) of the coordinator } \\
\text { towards the change }\end{array}$ & 0.290 & 3.001 & 0.004 & & & \\
\hline
\end{tabular}

Results showed in the first case that the combination of the two predictors explained $34.5 \%$ of the variation of the dependent variable. Both predictors were significant ( $p$-value $<0.05)$. The choice of the two predictors was made through a stepwise regression, adding one by one the supposed most important dimensions, looking at the correlation matrix.

Standard regression analysis was applied in the present paper in all the applications, despite the fact that our data came from a non-probabilistic sample. We were conducting pilot qualitative research, with elements chosen arbitrarily, making it impossible to either estimate the sampling variability or to identify possible bias. In this context, standard regression can still be used to summarize and explain relationships in data, if statistical inference from sample to population is no longer relevant. Moreover, in behavioral science, like in our case, it is hard to define a well specified model, able to determine high values of global variability [45]. In light of these considerations, the values of R2 around 0.3 may be considered satisfactory.

Endogeneity could also affect R2 values, as a consequence of estimation inconsistency. Errors in variables, omitted variables and simultaneous causality are the three instances for endogeneity [46]. 
The common method for dealing with simultaneity and endogeneity in linear regression is to use instrumental variables. However, finding appropriate instruments in social and behavioral surveys is difficult, if not impossible [47]. Furthermore, solving an endogeneity problem due to simultaneity is virtually impossible with cross-sectional data, because all variables are measured simultaneously [48].

It seems that since the healthcare operators felt supported by the organization (and even more by their coordinator) during the change process, they according felt more confident in expressing their ideas as to the ways the process itself could be performed. Therefore, their commitment also increases. This became possible as the management team took into account their working values, their objectives and opinions, as well as cared about their wellbeing within the working environment. Our empirical analysis supports H.1.

H.2b. The relation between the working excellence and the innovative organizational performances was mediated by the organizational climate.

In order to proof this hypothesis a preliminary regression analysis was performed to understand how the work excellence (connected to the quality of assistance) evaluated in H.1 may in turn affect the future expectations of the results in terms of achievable performance levels (on both the individual and organizational sides, see Tables 5 and 6). The result obtained in H.1 was encompassed into these second regressions (as a mediator $\mathrm{M}$ ). The independent variables identified for which the correlation resulted statistically significant were the "quality of communication" (considered under the perspective of its only dimension "safe working", meaning the capacity of keeping control over the working environment), and the "concerns" (considered under all its dimensions). The following regressions defined the causal relationships that will support the identification of the mediator.

Table 5. Regression analysis of the dependent variable "expectations of the result on individual innovative performances" (source: authors' elaboration).

\begin{tabular}{cccccccc}
\hline $\begin{array}{c}\text { Dependent } \\
\text { Variable }\end{array}$ & Explanatory Variables & $\boldsymbol{\beta}$ & $\boldsymbol{t}$-Test & $\boldsymbol{p}$-Value & $\mathbf{R}^{\mathbf{2}}$ & $\boldsymbol{F}$-Test & $\boldsymbol{p}$-Value \\
\hline $\begin{array}{c}\text { Expectations of the } \\
\text { result) related to } \\
\text { individual benefits }\end{array}$ & $\begin{array}{c}\text { (All the dimensions of) } \\
\text { concerns }\end{array}$ & -0.365 & -3.517 & 0.001 & 0.219 & 11.206 & 0.000 \\
\cline { 2 - 5 } & $\begin{array}{c}\text { Quality of communication: } \\
\text { safe working }\end{array}$ & 0.300 & 2.895 & 0.005 & & & \\
\hline
\end{tabular}

Table 6. Regression analysis of the dependent variable "Expectations of the result on the organization's innovative performances" (source: authors' elaboration).

\begin{tabular}{|c|c|c|c|c|c|c|c|}
\hline Dependent Variable & Explanatory Variables & $\beta$ & $t$-Test & $p$-Value & $\mathbf{R}^{2}$ & $F$-Test & $p$-Value \\
\hline \multirow{2}{*}{$\begin{array}{l}\text { (Expectations of the } \\
\text { result) related to } \\
\text { organizational benefits }\end{array}$} & $\begin{array}{l}\text { (All the dimensions of) } \\
\text { concerns }\end{array}$ & -0.392 & -3.858 & 0.001 & \multirow[t]{2}{*}{0.249} & \multirow[t]{2}{*}{13.105} & \multirow[t]{2}{*}{0.000} \\
\hline & Quality of communication & 0.312 & 3.065 & 0.005 & & & \\
\hline
\end{tabular}

Results pointed out on the one hand that if healthcare operators perceived an effective communication as to the potential future benefits coming with the collaboration between the new pediatrics operative units, both individual and organizational expectations increased affecting their performances in terms of e.g., professional capacity growth, improved relations between co-workers, better working efficiency and therefore better quality of the assistance delivered to patients (a positive and statistically significant relation). A climate among workers that, as said, positively impacts on patients makes these in turn better evaluate the performances of healthcare operators. Under such a perspective, the results of this study resemble those from previous works focused on the relations between a good work climate and the working performances [49], though in our study the "patients' evaluation of operators' performances" was not properly taken into account. 
On the other hand, expectations decreased if operators showed concerns as to the contents of the change, more specifically if they were afraid to lose their position (in part or completely) or to be assigned with new responsibilities (not followed by an equivalent compensation) (negative relation).

The overall proportion of the variation of the dependent variable explained by the combination of the independent ones was similar for the two situations analyzed: $21.9 \%$ at the individual level, while $24.9 \%$ at the organization level. This might suggest that all the operators shared the same (positive and negative) feelings as to the aspects encompassed by the change process. Apart from that, the mediation value \% was also obtained considering those from the interviewees that thoroughly answered the questionnaire.

H.3b. The relation between the innovative organizational performances and the organizational climate impacted on the quality of the healthcare delivery service.

Tables 7 and 8 show the results of the regression analysis that highlighted the influence of the variables "working satisfaction" and "quality of communication" on the variable "concerns" (in particular on its dimensions "concerns as to the change management modalities adopted" and "concerns for the future"). As seen in H.2, the concerns were in descriptive explanatory variables (as a mediator) of further expectations of achievable results.

Table 7. Regression analysis of the dependent variable "concern on the quality of service" (pt. I) (source: authors' elaboration).

\begin{tabular}{cccccccc}
\hline Dependent Variable & Variables & $\boldsymbol{\beta}$ & $\boldsymbol{t}$-Test & $\boldsymbol{p}$-Value & $\mathbf{R}^{2}$ & $\boldsymbol{F}$-Test & $\boldsymbol{p}$-Value \\
\hline $\begin{array}{c}\text { (Concerns) as to the } \\
\text { change management } \\
\text { modalities adopted }\end{array}$ & $\begin{array}{c}\text { Quality of } \\
\text { communication }\end{array}$ & -0.289 & -2.548 & 0.013 & 0.071 & 6.493 & 0.001 \\
\hline
\end{tabular}

Table 8. Regression analysis of the dependent variable "concern of the future on the quality of service" (pt. II) (source: authors' elaboration).

\begin{tabular}{cccccccc}
\hline Dependent Variable & Variables & $\boldsymbol{\beta}$ & $\boldsymbol{t}$-Test & $\boldsymbol{p}$-Value & $\mathbf{R}^{2}$ & $\boldsymbol{F}$-Test & $p$-Value \\
\hline (Concerns) for the future & $\begin{array}{c}\text { Working } \\
\text { satisfaction }\end{array}$ & -0.262 & -2.286 & 0.025 & 0.055 & 5.224 & 0.001 \\
\hline
\end{tabular}

Results highlighted that the quality of communications had in particular a negative and statistically significant relationship with the concerns as to the change management modalities adopted. The proportion of the variation of the dependent variable explained by this predictor was 7.1\%: this might imply that the concerns expressed by healthcare operators decreased when they felt that they had been kept updated as to the reasons and the progresses of the change process, and when they could share their point of view on the process with the management.

Another negative and statistically significant relation occurred instead between the positive emotions that came from a satisfying working environment and the concerns for the future. The proportion of the variation of the dependent variable explained by this predictor was $5.5 \%$ : it suggested that when healthcare operators felt supported, especially from their coordinator, during the change process, and in addition to their coordinator welcoming and adopting proposals made by the operators, these latter felt more comfortable in their working environment, so their concerns for the future decreased.

H.4b. A safety (organizational) climate resulted from the transformation of the characteristics of work through a timely commitment.

In order to proof this hypothesis a regression analysis was performed to understand whether the variable "quality of communication", broadening its dimension of safe working analyzed in H.3, can 
depend on the variables "characteristics of work" (especially on its three autonomy-based dimensions) and "commitment to change" (see Table 9).

Table 9. Regression analysis of the dependent variable "quality of communication on the safety (organizational) climate" (source: authors' elaboration).

\begin{tabular}{cccccccc}
\hline $\begin{array}{c}\text { Dependent } \\
\text { Variable }\end{array}$ & $\begin{array}{c}\text { Explanatory } \\
\text { Variables }\end{array}$ & $\boldsymbol{\beta}$ & $\boldsymbol{t}$-Test & $\boldsymbol{p}$-Value & $\mathbf{R}^{2}$ & $\boldsymbol{F}$-Test & $\boldsymbol{p}$-Value \\
\hline $\begin{array}{c}\text { Quality of } \\
\text { communication }\end{array}$ & $\begin{array}{c}\text { Characteristics } \\
\text { of work }\end{array}$ & 0.494 & 4.699 & 0.001 & & & \\
\cline { 2 - 6 } & $\begin{array}{c}\text { Commitment to } \\
\text { change }\end{array}$ & 0.342 & 3.238 & 0.002 & & 12.951 & 0.001 \\
\hline
\end{tabular}

According to the results, both predictors showed a positive and statistically significant relation with the dependent variable. The overall proportion of the variation of the dependent variable explained by the combination of the independent ones was $24.7 \%$ : it could mean that the experience of an improvement in the working wellbeing made the healthcare operator increasingly aware of the (acknowledged) importance of their role within the organization and accordingly of the need to develop a more autonomous approach to their duties. This eventually led to a more complete vision of the working environment, that hopefully provoked in turn an improvement of their quality of life within the organization they felt like they were part of.

\subsection{Observation of the Daily Activities (Qualitative Aspects)}

As seen in Figure 2, a series of focus groups was conducted during the first months of the change process to get more specific information as to the existing working dynamics within the pediatric ward, in order to:

- measure the time spent by nurses and social workers in their specific tasks during the morning and afternoon shifts (direct and indirect assistance to the patient);

- measure the time spent for working activities inside and outside the ward;

- identify eventual time wastes, meaning the amount of time used to perform "resource-absorbing but not value-creating" activities;

- describe the extent of integration between the tasks of the different healthcare operators (doctors/nurses/social workers).

The observation was performed by means of the "shadowing" technique: researchers external to the organization observed nurses and social workers during four working shifts, transcribing for each activity the time and the place in which they were performed. The observation showed that nurses spent on the average $50 \%$ of their morning shift close to the patient's bed for e.g., generic assistance, management of therapy, monitoring or collaboration. The remaining $50 \%$ addressed activities of indirect assistance, e.g., drugs preparation or data recording on the patient file. On the contrary, the amount of time spent by the social worker close to the patient's bed was likely to be higher, since they have to address the basic needs of the patient. The collaboration of the nurse and the social worker for the same patient was only observed for the most complex cases. No relevant time wastes were eventually noticed.

\section{Second Survey Results (T2)}

A second survey was administered to the same subjects by the end of the experience, in order to understand whether the change process-also deployed on the basis of the results emerged at T1-impacted positively on the organizational performances. In particular, some among the HRM-based variables described in Figure 2 and in Table 2 were further investigated, i.e., "quality of the clinical practice" (under all its dimensions), "relationship with the patient", and "intention of turnover" (under 
all its dimensions). The main purpose was to assess their influence on a new set of HRM-based variables, i.e., "proactivity" and "innovative behavior at work", whose analysis could not be performed until the change process had produced some actual results (e.g., the nurses training programs, as described in Figure 2).

Table 10 compares the mean values and the standard deviation of the "relationship with the patient" variable between T1 and T2, from which emerges an increased relational quality between the patient and the healthcare operator. The number of observations was different in the two surveys: $\mathrm{n} 1$ $=153$ and $\mathrm{n} 2=115$.

Table 10. Comparison of the values between $\mathrm{T} 1$ and $\mathrm{T} 2$ (source: authors' elaboration).

\begin{tabular}{ccccc}
\hline Variable & Mean Value (T1) & SD (T1) & Mean Value (T2) & SD (T2) \\
\hline $\begin{array}{c}\text { Relationship with } \\
\text { the patient }\end{array}$ & 4.05 & 0.79 & 4.30 & 0.75 \\
\hline
\end{tabular}

A t-test for the correlated samples was instead performed for the comparison of the "quality of the clinical practice" variable between T1 and T2, in order to assess the mean values of the dimensions of the variable. To this end, the data were gathered from 47 healthcare operators that answered to both survey questionnaires. A comparison of the two mean values through the t-test suggested that their difference was significant, showing an increase from T1 to T2.

In general, healthcare operators at $\mathrm{T} 2$ perceived a better quality and suitability of assistance. A more fruitful collaboration was registered as well between the different professional figures (doctor and nurse, or nurse and social worker). More specifically, from a further analysis of the differences between T1 and T2 of the mean values of the items related to the variable, emerged that nurses have more time to spend with the patients, and their opinions as to patients' treatments were more favorably welcomed by the doctors (see Table 11).

Table 11. Comparison of the values between T1 and T2 (source: authors' elaboration).

\begin{tabular}{ccccc}
\hline Variable & Dimensions & Mean Value (T1) & Mean Value (T2) & $\boldsymbol{t}$-Test Result \\
\hline \multirow{2}{*}{$\begin{array}{c}\text { Quality of clinical } \\
\text { practice }\end{array}$} & $\begin{array}{c}\text { Quality of } \\
\text { assistance }\end{array}$ & 3.61 & 4.30 & -2.514 \\
\cline { 2 - 5 } & $\begin{array}{c}\text { Suitability of } \\
\text { assistance }\end{array}$ & 2.19 & 2.59 & -3.650 \\
\cline { 2 - 5 } & $\begin{array}{c}\text { Collaboration } \\
\text { between doctors } \\
\text { and nurses }\end{array}$ & 2.47 & 2.87 & -3.326 \\
\hline
\end{tabular}

As said, two new variables were introduced in the second survey, following the hypothesis that the change process may have acted as a structural determinant of organizational innovativeness [50]. Tables 12 and 13 report for each of the dimensions they comprise the mean value, the standard deviation, as well as the Cronbach alpha value. This test analysis could be used to identify the possible mediators in our further impact analysis.

Table 12. Evaluation of the new variable "innovative behavior at work" (source: authors' elaboration).

\begin{tabular}{cccc}
\hline Dimensions of the Variable & Mean Value & SD & Cronbach Alfa \\
\hline Generation of ideas & 2.77 & 0.77 & 0.87 \\
Promotion of ideas & 2.74 & 0.73 & 0.79 \\
Realization of ideas & 2.85 & 0.75 & 0.79 \\
\hline
\end{tabular}


Table 13. Evaluation of the new variable "proactivity" (source: authors' elaboration).

\begin{tabular}{cccc}
\hline Dimensions of the Variable & Mean Value & SD & Cronbach Alfa \\
\hline Individual level & 2.98 & 0.55 & 0.68 \\
Group level & 2.83 & 0.66 & 0.77 \\
Organization level & 2.61 & 0.76 & 0.87 \\
\hline
\end{tabular}

The healthcare operators involved declared to have started new and innovative behaviors at work in the last six months of the experimentation, as the result of the organization of nursing training programs, as well as through, e.g., the complete set up of instruments for assistance planning and therapeutic education. This made possible for them to get to original solutions to problems, to be more easily supported by co-workers towards the introduction of new ideas, as well as the systematic transformation of innovative ideas in actual working elements and components. Such a result confirms what already emerged from the analysis of the research hypotheses in the first survey, which is that a good organizational climate, when combined with a greater participation to the organizational development of the working environment, plays as a mediator of productivity and pushes towards higher rates of performance in the entire system.

The healthcare operators also declared to have developed new and better methods for group working, for enhancing their work groups' performances, as well as for introducing significant changes to accomplish their tasks.

\section{Correlation and Regression Analysis at T2}

Correlations were computed at $\mathrm{T} 2$ between the variables investigated and these are reported in Table A4 of the Appendix A. From the correlation matrix, we can summarize the following most significant results (Table 14):

Table 14. Correlations in T2 (source: authors' elaboration).

\begin{tabular}{lc}
\hline \multicolumn{1}{c}{ Variables } & Correlation Coefficient r \\
\hline \multicolumn{2}{c}{ Correlation of “Generation of Ideas” with: } \\
\hline - Collaboration between doctors and nurses (quality of the clinical practice) & +0.336 \\
- Individual level (proactivity) & +0.620 \\
- Organization level (proactivity) & +0.713 \\
- Professional (intention of turnover) & -0.309 \\
- Inside the organization (intention of turnover) & -0.317 \\
\hline
\end{tabular}

To mitigate the endogeneity matter, we reduced the possible impact of reverse causality by adopting a dependent variable taken at time $\mathrm{T} 2$, whereas the independent variables were assessed at time T1.

Tables 15 and 16 describe the results of the regression analyses conducted to understand the impact of HRM-based variables measured at T1 on the dimensions of the variable "quality of clinical practice" measured at T2. In particular, Table 15 shows the impact of the variables "perceived organizational support", "expectation of result", and "concerns" on the quality of assistance. The first two of those are also described in Table 16 in relation to the suitability of assistance.

A substantial agreement can therefore be found with H.1 also at T2. In the first case (Table 15), the results show that only the perceived organizational support had a positive and statistically significant relation with the quality of assistance, whereas a negative relation emerged as to the concerns to cope with the change and the expectation of result. This means that the quality of assistance was affected by two opposite pushes: on one hand the operators could be more inclined to increase the quality level of their work as they felt supported by the coordinator all along the change process, but on the other hand their enthusiasm could risk being softened if they were not able to fully interpret the extent of 
the same process. The overall proportion of the variation of the dependent variable explained by the combination of the predictors was $25.7 \%$.

Table 15. Regression analysis of dependent variable "quality of assistance on the quality of care" (source: authors' elaboration).

\begin{tabular}{|c|c|c|c|c|c|c|c|}
\hline $\begin{array}{c}\text { Dependent } \\
\text { Variable at } \mathrm{T} 2\end{array}$ & Explanatory Variables at T1 & $\beta$ & $t$-Test & $p$-Value & $\mathbf{R}^{2}$ & $F$-Test & $p$-Value \\
\hline \multirow{3}{*}{$\begin{array}{l}\text { (Quality of clinical } \\
\text { practice)—quality of } \\
\text { assistance }\end{array}$} & $\begin{array}{l}\text { (Perceived organizational } \\
\text { support) of the coordinator } \\
\text { towards the change; }\end{array}$ & -0.382 & 2.135 & 0.002 & \multirow{3}{*}{0.257} & \multirow{3}{*}{6.061} & \multirow{3}{*}{0.000} \\
\hline & $\begin{array}{l}\text { (Concerns) as to the } \\
\text { individual capacity to cope } \\
\text { with the change }\end{array}$ & 0.342 & 2.135 & 0.100 & & & \\
\hline & $\begin{array}{l}\text { (All the dimensions of) the } \\
\text { expectations of the result }\end{array}$ & -0.361 & -2.663 & 0.010 & & & \\
\hline
\end{tabular}

Table 16. Regression analysis of the dependent variable "suitability of assistance on the adequacy of assistance" (source: authors' elaboration).

\begin{tabular}{cccccccc}
\hline $\begin{array}{c}\text { Dependent } \\
\text { Variable at T2 }\end{array}$ & Explanatory Variables at T1 & $\boldsymbol{\beta}$ & $\boldsymbol{t}$-Test & $\boldsymbol{p}$-Value & $\mathbf{R}^{2}$ & $\boldsymbol{F}$-Test & $\boldsymbol{p}$-Value \\
\hline $\begin{array}{c}\text { (Quality of clinical } \\
\text { practice)_quality of } \\
\text { assistance }\end{array}$ & $\begin{array}{c}\text { (All the dimensions of) the } \\
\text { expectations of the result }\end{array}$ & -0.466 & -4.020 & 0.008 & & & \\
\cline { 2 - 6 } & $\begin{array}{c}\text { (Perceived organizational } \\
\text { support) of the organization }\end{array}$ & 0.461 & 3.975 & 0.006 & & 16.224 & 0.001 \\
\hline
\end{tabular}

Similar dynamics emerged in the second case (Table 16): a suitable assistance to patients was as well affected positively by trust in the organization and negatively by the difficulties healthcare operators cope with in realizing their nurtured expectations. The two effects had a compensatory impact on the dependent variable. The overall proportion of the variation of the dependent variable explained by the combination of the predictors was $40.9 \%$.

Table 17 shows how the variable "concerns" measured at T1 has an impact on the variable "proactivity" measured at $\mathrm{T} 2$.

Table 17. Regression analysis on proactivity (individual and group) (source: authors' elaboration).

\begin{tabular}{cccccccc}
\hline $\begin{array}{c}\text { Dependent } \\
\text { Variable at T2 }\end{array}$ & Explanatory Variables at T1 & $\boldsymbol{\beta}$ & $\boldsymbol{t}$-Test & $\boldsymbol{p}$-Value & $\mathbf{R}^{\mathbf{2}}$ & $\boldsymbol{F}$-Test & $\boldsymbol{p}$-Value \\
\hline $\begin{array}{c}\text { (Proactivity) at } \\
\text { individual and } \\
\text { group level }\end{array}$ & $\begin{array}{c}\text { (Concerns) as to handling the } \\
\text { change }\end{array}$ & -0.303 & -2.088 & 0.043 & 0.710 & 4.360 & 0.001 \\
\hline
\end{tabular}

The dimension "handling the change" was the only one to have a negative and statistically significant relation on the proactivity, able to explain $71 \%$ of the variability of the dependent variable. This means that feeling part of the change process helps the organizational climate to thrive, in substantial agreement to what stated by H.2.

Table 18 shows the results of the regression analysis that highlights the influence of the variables "characteristics of work" on the variable "innovative behavior at work" (in particular on its dimension "generation of ideas"). The results confirm also for T2 the research hypotheses H.3 and H.4. 
Table 18. Regression analysis on innovative behavior at work (idea generation) in T2 (source: authors' elaboration).

\begin{tabular}{cccccccc}
\hline $\begin{array}{c}\text { Dependent } \\
\text { Variable at T2 }\end{array}$ & Explanatory Variables at T1 & $\boldsymbol{\beta}$ & $\boldsymbol{t}$-Test & $\boldsymbol{p}$-Value & $\mathbf{R}^{2}$ & $\boldsymbol{F}$-Test & $\boldsymbol{p}$-Value \\
\hline $\begin{array}{c}\text { (Innovative } \\
\text { behavior at work) } \\
\text { identity of the task }\end{array}$ & -0.706 & -3.670 & 0.003 & & & \\
\cline { 2 - 5 } $\begin{array}{c}\text { Generation of ideas } \\
\text { (Characteristics of work) } \\
\text { autonomous work } \\
\text { scheduling, choice of the } \\
\text { work method, decision } \\
\text { making; identity of the task }\end{array}$ & 0.524 & 20.724 & 0.002 & 0.200 & 6.739 & 0.000 \\
\hline
\end{tabular}

The overall proportion of the variation of the dependent variable explained by the combination of the predictors was $20 \%$. Healthcare operators that were able from the beginning to perform their tasks under a (multiple) perspective of autonomy resulted accordingly much more capable to bring innovativeness in the new organizational context. On the other hand, the identity of work, meant as the basic "accomplishing the task requested", related negatively with a proactive and innovative behavior, and then with the capacity to establish a safety (organizational) climate. This also confirms the perception of the climate as a "psychological atmosphere" that originates from the organizational routines (breakthrough) [51].

All remarks made on the low value of R2 in the regression in Section 4.2 may also be applied for the previous outputs.

\section{Discussion}

Recognizing the connection between the change management and the performance level inside an organization and the consequent importance of the "organizational climate" perceived by the workers as related to an evolving working environment [38] have led the hospital management to focus on the climate as a possible mediator between the two mentioned elements, so as to understand the mutual impact and determine the actions to undertake in order to improve the day-by-day life of the organization under many angles.

The analysis of the results showed that in the first part of the process of change between the HRM variables of Table 3, those that mainly influenced the organizational climate were the "perceived organizational support" and the "quality of communication". This highlighted how within the pediatric department, the organizational perspective (management and workforce) was prevalent compared to the individual one (individual performance and work dynamics).

Summarizing, the first survey administration shed light on the following aspects:

- a moderate organizational wellbeing among healthcare operators, in terms of a perceived autonomy as to decision making, work scheduling, and choice of the work methods. This helped them to better cope with the variety of their tasks;

- a low level of satisfaction as to the dynamics of collaboration between different professional figures. This was also confirmed in the focus groups;

- a sufficient quality of assistance, not always adequate to patients' needs, but improvable anyway;

- a good relationship with the patients, that made the operators involved feel strongly emotionally linked to their operative unit;

- a sufficient sense of support from the organization, much better from the coordinator during the phases of change;

- a low intention of leaving the work, despite enduring concerns as to handling the change and understanding the overall extent of the change process.

The regression analyses performed at $\mathrm{T} 1$ showed that there was a positive relation between feeling supported by the organization and a good quality of assistance, as well as with a lesser concern for 
the future. Such feeling led in fact the worker to be willing to help the organization in coping with the change, to increase their efforts (so achieving better performances), to adopt a loyal behavior towards the organization by accepting its norms and rules and becoming at the same time trustful and trustworthy to the organization [52].

Many studies proved that the management, by entrusting workers with responsibility roles and supporting coordinators, is able to meaningfully influence performances at the individual, group and organizational level [53-55]: supporting and motivating people towards the organizational change leads in fact to the development of a sense of engagement and makes easier the compliance to the change itself.

The research also showed that good communication made people increase their expectations as to both individual and organizational benefits and lower their concerns about the ways to handle the change. In this sense, communication suggested feelings of tranquility, continuity, stability and at the same time, innovation and evolution [56].

Another important feature of the innovation was related to positive interpersonal exchanges where each one was free to express their opinions $[57,58]$. This could mean that organizations have to provide adequate information about the change, in order to meaningfully reduce anxiety and uncertainty and to promote positive expectations towards the future outcomes of the change process [59].

Being conscious about the reasons and the dynamics of change helped healthcare operators to lower concerns about the idea of the "new". To this aim, several studies showed that when people received clear and thorough information about the change process performed by the organization, they resulted as more inclined to promote and support the actions of the change, experiencing positive consequences in terms of satisfaction at work, psychological wellbeing and commitment [60].

All these points recommend the importance of establishing a communicational circularity and of using strategies able to leverage the active participation of the worker involved in the path of organizational change. Moreover, a high-quality communication instils a wide sense of trust towards the future positive effects coming with the change itself.

Overall, what emerged from the study was the clear perception of how the organizational climate (especially through its related features) was a means to achieving optimal goals of organizational performances: in other words, climate was not one of those organizational variables whose behavior depended on (individual as well as organizational) dynamics, but rather an actual mediator of the productivity of the system, or better yet as the final outcome of a path that intertwined in many ways the excellence of work with the path towards innovation. The regressions estimated in T1 support this finding.

By the end of the experience-and presumably after a correct process of preparation to the change-the organizational climate resulted as mainly affected by the variables "expectation of result (related to individual benefit)" and "concerns (as to handling the change)". The negative correlation with the dependent variables points out for both the capacity showed by each worker in recognizing the effort of the management to guarantee continuity to their performances; whereas in fact a lesser understanding of the overall change process was observed, a decrease of the level of performance occurred, up to the manifested intention in some cases of leaving the organization, which endangered the entire project.

The second survey administration highlighted some important aspects perceived by the healthcare operators involved:

- the new organization of the ward-two level II operative units coordinated by a supervising level I operative unit—brought a higher level of quality and suitability to the assistance;

- enough time available for doctors and nurses to deliberate ideas as to patients' issues, and to deliver more suitable health and care services;

- a general increased sense of belonging to the organization and working satisfaction, despite the unchanged number of workers in front of the increased size of the structure. 
New variables ("innovative behavior at work" and "proactivity") were introduced and evaluated to prove that the change process could ignite organizational innovativeness [61]: those in fact among the healthcare operators that tried from the beginning to become more autonomous in performing their duties, improved over time their skills in decision making, problem solving and creative thinking. Amabile et al. [62] found a significant positive correlation between autonomy and creative behavior: a higher rate of autonomy allows workers to commit to tasks that sometimes require a non-conventional approach [63].

On the other hand, the regression analysis conducted at $\mathrm{T} 2$ also pointed out that the operators that showed at $\mathrm{T} 1$ their concerns as to handling the change and/or understanding the overall change picture, did not develop over time proactive behaviors. To this aim, the literature has shown on many occasions the relation between a scarce proactivity and a certain predisposition to anxiety at work [51,64]. In addition, increasing concerns can even result, as observed, in a drastic decision to leave the organization. Dong et al. [65] conduced a longitudinal study whose main objective was to identify which between individual factors, working conditions and eventual health issues may be more likely to lead a nurse to the decision to leave their workplace, or to increase the rate of absenteeism. The results showed the importance of considering the eventual effects of organizational changes on the workers' behavior, as much as better working conditions, as critical factor to a better health status, which can help prevent the intention to leave.

\section{Limitations of the Study}

The findings of this study should of course be interpreted within the context of its limitations. First, the observations came from a single organization (although large sized and over a long period of time) and the extent to which they were representative of organizations in general, or even of service organizations in general, could only be determined by reference to the work of other researchers. Finally, the mediation model described was not the only model that could have been constructed to fit the observed data; it is well known that a causal model can usually be replaced by one or more equivalent models with identical fit characteristics and the choice of model rests on substantive and theoretical considerations [66].

In the present case, reversing the direction of the causal flow between the climate and performance would lead to a theoretically plausible model in which performance is the mediating variable, that is, effective HRM decisions enhancing performance, which in turn leads to positive employee attitudes. To this end, in fact, West et al. [67] concluded that climate was an outcome of performance rather than a cause. Nevertheless, on the other hand, Ryan et al. [68] found the direction of the link between morale and productivity to be indeterminate, and more emphatically, Koys [69] found clear evidence that climate causes performance; specifically, employee satisfaction predicted subsequent customer satisfaction and organizational citizenship behavior predicted subsequent profits (rather than the other way round). Furthermore, Anderson and West [70] found that significant relationships between climate, HRM factors and performance remained, also removing the influence of prior performances.

Finally, we noticed that the mediation model presented here was almost certainly a considerable simplification of the complex system of causal, and possibly mutual, relations that characterize a healthcare organization like the one investigated. The point also leads to state that, under many perspectives, the joint role of climate and employee satisfaction as mediators between HRM and performance remains to be established empirically.

\section{Conclusions}

Change processes have largely characterized healthcare organizations in recent years. This was especially due to the presence of a growing number of competitors in the "quasi-market" of healthcare (extra-regional and/or private facilities, see e.g., [71-73], to the spreading of a different idea of user/patient, increasingly aware of their roles and their rights, as well as to the technological progress capable of bringing continuous transformations in terms of production processes and of suggesting 
improvements in terms of organizational forms. All the mentioned phenomena are nonetheless very hard to be undertaken without properly taking into account the underlying human and relational dynamics. An effective process of change needs therefore to carefully consider not only the "technical" contents, but also the surrounding "human factors" that can actually facilitate their realization: this is the way through which changes can become innovations.

In this case study, the deployment of (the first two phases of) the AR method for investigating organizational climate through a HRM-based perspective allowed us to evaluate and monitor the change process for:

- the healthcare operators (doctors, nurses, social workers) in terms of individual characteristics (attitudes, perceptions and behaviors), the work climate, the capacity of collaboration and the organizational support for improving their compliance with the norms and rules of the change process;

- the patients, in terms of the continuity of care, safety, quality of assistance and the overall satisfaction of the cure and care aspects.

The following objectives showed how the work hypotheses were accomplished thanks to the role of the organizational climate in the relationship between working excellence and organizational innovation:

- evaluating the complexity of the assistance of patients by means of a set of timely and concise criteria;

- improving the comparison and the integration between the different professional figures thanks to the shared development of clinical paths;

- $\quad$ setting up shared formative interventions focused on the most common issues raised by patients and medical teams;

- identifying and implementing an organizational model that makes possible for all workers the creation of and participation to paths of professional growth.

This variable is a possible candidate of mediator, that needs to be confirmed by the data, when survey planning is completed.

To summarize, what emerged from the study was the creation of a model of organization and behavior that, paraphrasing from the mechanical engineering, goes by the name of "friction process" [74]: individuals on the one hand move towards an increasing "coherence" with the organization, while on the other hand the organization itself tries to "remedy" to the initial incomprehension with the employees by adopting ad hoc internal attitudes and policies.

The analysis of the climate in the healthcare organizations increased, on the one hand, the welfare status for a highly knowledge-intensive context; on the other hand, it supported the organization to achieving specific management targets. In particular, the analysis was aimed at monitoring and understanding the health status of patients and operators within the organizational unit involved, in order to exploit the change dynamics and, more generally, appropriate strategies for continuous improvement. The analysis pointed out as well the strengths and weaknesses stemming from the process of knowledge and identity development for the citizens and the all operators involved. The main aim was to build a solid information framework for planning and implementing the mentioned change dynamics at each level of the organization. The project introduced is part of the whole set of activities currently in progress within the hospital, especially in terms of efficacy and appropriateness of the clinical performances, oriented to provide high levels of assistance delivered to the entire community, by means of a timely integration between the healthcare operators and to raise up consequently their competences and awareness of the fundamental tasks they are called to deal with.

After all, as observed by Kreitner and Kinicki [60], the main goal of the management is to "work with and through employees to achieve objectives for the organization": it becomes so clear once more that setting up a good organizational climate becomes a necessary (though not sufficient) condition to 
create an expert, structured and balanced workforce (organizational innovation), thus motivated and capable of achieving great performances (working excellence) aligned with the organization's interests and objectives. In other words, the organizational climate represents the result of a timely way to set up the work, that balances duties and compensations through the mutual respect between the different types of workers (structure), controlling potential situations of conflict (implicit or manifest) that may affect the single resource as well as the overall quality of their work.

The recent and ongoing economic and social changes are pushing healthcare organizations to a continuous improvement of their services, with specific attention to the quality of the service provided, the clinical care and the cost containment. In this perspective, the development of systems and management mechanisms appears to be particularly important, as they support the involvement and empowerment of human resources in general processes of change and improve the services provided.

The important roles of mission, vision and strategy have been heavily emphasized in most of today's organizations in order to maintain a business sustainability performance in the long term. [75].

As a direct consequence, the analysis and management of the organizational climate and its components appear as highly relevant, as shown by many studies, not only because of the strong correlations between the level of employee satisfaction, the organizational climate and the users' satisfaction, but also because in the presence of an organizational change, climate studies prove to be an essential support as an approach to an analysis of change and as a vehicle for change itself.

The achievement of positive organizational performances can be achieved with fluid, efficient, effective and technological processes but also must be also related to the workforce- the human component- to achieve an efficient and effective management of the work process [76].

The present research aimed at providing an analysis of the organizational climate within a healthcare organization involved in a process of continuous improvement of its diagnosis, treatment and care paths, in order to increase the quality of the services offered. At the time of the survey the prospects for the future were satisfactory, yet it remains necessary to work towards the prevention of the consolidation of disillusionment feelings and detachment phenomena.

Author Contributions: All authors contributed equally to the development of this research and are listed in alphabetical order. All authors have read and agreed to the published version of the manuscript.

Funding: This research received no external funding.

Conflicts of Interest: The authors declare no conflict of interest.

\section{Appendix A}

Table A1. Work design questionnaire (HRM-related work features and corresponding items) (source: authors' elaboration).

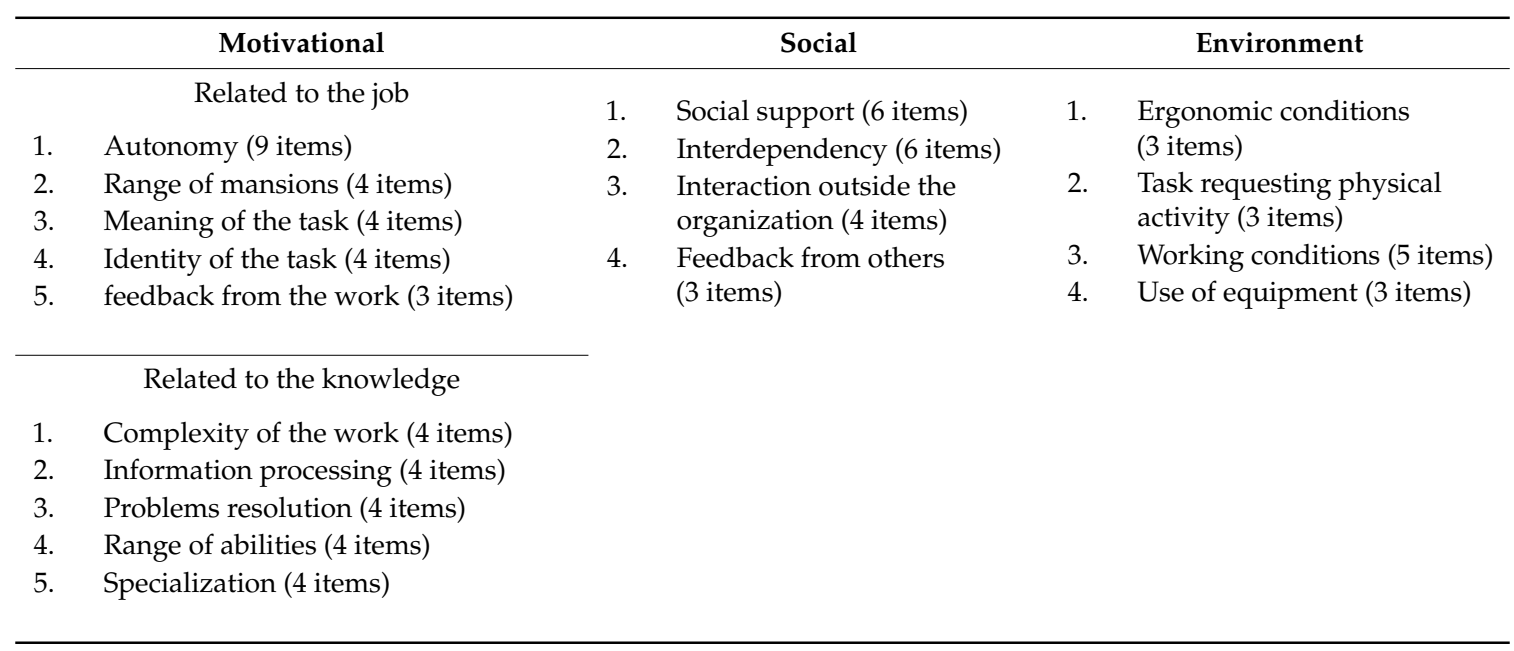


Table A2. HRM-based variables measured at T1 and T2 (the beginning and the end of the research experiment (source: authors' elaboration).

\begin{tabular}{cc}
\hline $\begin{array}{c}\text { Variables Measured at T1 } \\
\text { (May 2014) }\end{array}$ & $\begin{array}{c}\text { Variables Measured at T2 } \\
\text { (May 2017) }\end{array}$ \\
\hline Characteristics of work \\
Working satisfaction \\
Quality of clinical practice \\
Relationship with the patient \\
Organizational commitment \\
$\begin{array}{c}\text { Perceived organizational support } \\
\text { Quality of communication } \\
\text { Intention of turnover } \\
\text { Working uncertainty } \\
\text { Expectations of result } \\
\text { Concerns } \\
\text { Practical help }\end{array}$ \\
Commitment to change \\
\\
\end{tabular}


Table A3. Correlations between the variables studied at T1 (source: authors' elaboration).

\begin{tabular}{|c|c|c|c|c|c|c|c|c|c|c|c|c|c|c|c|c|c|c|c|c|c|c|c|c|c|c|c|}
\hline & 1 & 2 & 3 & 4 & 5 & 6 & 7 & 8 & 9 & 10 & 11 & 12 & 13 & 14 & 15 & 16 & 17 & 18 & 19 & 20 & 21 & 22 & 23 & 24 & 25 & 26 & 27 \\
\hline $\begin{array}{l}1 \mathrm{Au} \\
2 \mathrm{Var}\end{array}$ & $\begin{array}{c}1 \\
\left.0.2344^{*}\right)\end{array}$ & 1 & & & & & & & & & & & & & & & & & & & & & & & & & \\
\hline 3 Id & $\begin{array}{l}0.659 \\
(* *)\end{array}$ & 0.138 & 1 & & & & & & & & & & & & & & & & & & & & & & & & \\
\hline 4 Sod & $\left.0.2611^{*}\right)$ & 0.255 (*) $^{*}$ & $\begin{array}{c}0.326 \\
(* *)\end{array}$ & 1 & & & & & & & & & & & & & & & & & & & & & & & \\
\hline 5 Qual & 0.201 & 0.235 (*) $^{*}$ & 0.169 & 0.065 & 1 & & & & & & & & & & & & & & & & & & & & & & \\
\hline $6 \mathrm{Ad}$ & $0.277^{(*)}$ & -0.024 & $\begin{array}{c}0.334 \\
(* *)\end{array}$ & $\begin{array}{c}0.472 \\
(* *)\end{array}$ & 0.211 & 1 & & & & & & & & & & & & & & & & & & & & & \\
\hline $7 \mathrm{Col}$ & $\left.0.2722^{*}\right)$ & 0.211 & $\begin{array}{c}0.339 \\
(* *)\end{array}$ & $\begin{array}{c}0.432 \\
(* *)\end{array}$ & 0.094 & $\begin{array}{c}0.690 \\
(* *)\end{array}$ & 1 & & & & & & & & & & & & & & & & & & & & \\
\hline 8C_af & $\underset{(* 4 *)}{0.458}$ & $\begin{array}{c}0.334 \\
(* *)\end{array}$ & $\begin{array}{c}0.376 \\
(* *)\end{array}$ & $\begin{array}{l}0.465 \\
(* *)\end{array}$ & 0.132 & $\begin{array}{l}0.319 \\
(* *)\end{array}$ & $\begin{array}{l}0.487 \\
(* *)\end{array}$ & 1 & & & & & & & & & & & & & & & & & & & \\
\hline 9 C_co & $\begin{array}{c}0.321 \\
\left(*^{* *}\right)\end{array}$ & -0.038 & $\begin{array}{l}0.427 \\
(* *)\end{array}$ & 0.082 & 0.093 & -0.028 & -0.03 & $\begin{array}{l}0.287 \\
\left({ }^{*}\right)\end{array}$ & 1 & & & & & & & & & & & & & & & & & & \\
\hline 10 C_no & $\begin{array}{l}0.445 \\
(* *)\end{array}$ & 0.165 & $\begin{array}{c}0.366 \\
(* *)\end{array}$ & $\begin{array}{c}0.331 \\
(* *)\end{array}$ & 0.167 & 0.163 & $\underset{(*)}{0.234}$ & $\begin{array}{c}0.547 \\
(* *)\end{array}$ & $\begin{array}{l}0.432 \\
(* *)\end{array}$ & 1 & & & & & & & & & & & & & & & & & \\
\hline 11 Su_o & $\begin{array}{l}0.350 \\
(* *)\end{array}$ & 0.16 & $\begin{array}{l}0.286 \\
(*)\end{array}$ & $\begin{array}{l}0.362 \\
(* *)\end{array}$ & $0.356^{(* *)}$ & $\begin{array}{l}0.530 \\
(* *)\end{array}$ & $\begin{array}{l}0.906 \\
(* * *)\end{array}$ & $\begin{array}{c}0.428 \\
(* *)\end{array}$ & 0.133 & $\begin{array}{l}0.341 \\
(* *)\end{array}$ & 1 & & & & & & & & & & & & & & & & \\
\hline $12 \mathrm{Su} \_\mathrm{c}$ & $0.281\left(^{*}\right)$ & -0.105 & $\begin{array}{c}0.358 \\
(* *)\end{array}$ & 0.156 & -0.051 & $\begin{array}{c}0.370 \\
(* *)\end{array}$ & $\begin{array}{c}0.307 \\
(* *)\end{array}$ & 0.09 & 0.057 & 0.215 & 0.166 & 1 & & & & & & & & & & & & & & & \\
\hline $13 \mathrm{Com}$ & $\left.0.2600^{*}\right)$ & 0.063 & $\begin{array}{l}0.477 \\
(* *)\end{array}$ & $\begin{array}{c}0.408 \\
(* *)\end{array}$ & $0.4333^{*}$ & & $0.4 * 15$ & 0.322 & 0.068 & $\begin{array}{l}0.31 \\
(* *)\end{array}$ & $\begin{array}{l}0.477 \\
(* *)\end{array}$ & $\begin{array}{c}0.357 \\
(* *) \\
(* *)\end{array}$ & 1 & & & & & & & & & & & & & & \\
\hline 14 Ins & -0.033 & 0.032 & -0.146 & -0.137 & 0.063 & -0.06 & -0.086 & -0.118 & -0.176 & -0.224 & 0.047 & -0.177 & -0.169 & 1 & & & & & & & & & & & & & \\
\hline $15 \mathrm{~A}_{-}$ind & 0.104 & $\begin{array}{c}0.324 \\
(* *)\end{array}$ & 0.157 & $\begin{array}{c}0.395 \\
(* * *)\end{array}$ & -0.078 & 0.104 & $\begin{array}{l}0.290 \\
(*)\end{array}$ & $\begin{array}{c}0.383 \\
(* *)\end{array}$ & 0.072 & $\begin{array}{c}0.251 \\
(*)\end{array}$ & 0.18 & -0.035 & $\begin{array}{c}0.328 \\
(* *)\end{array}$ & $\begin{array}{c}-0.320 \\
(* *)\end{array}$ & 1 & & & & & & & & & & & & \\
\hline 16 A_org & 0.103 & $0.260\left(^{*}\right)$ & 0.136 & 0.413 & -0.092 & 0.22 & $\begin{array}{l}0.323 \\
\left(*^{*}\right)\end{array}$ & 0.343 & 0.104 & $\begin{array}{c}0.279 \\
(*)\end{array}$ & 0.159 & 0.105 & $\begin{array}{c}0.341 \\
(* *)\end{array}$ & -0.412 & $\begin{array}{c}0.811 \\
\left({ }^{* *}\right)\end{array}$ & 1 & & & & & & & & & & & \\
\hline 17 P_cap & -0.129 & -0.234 & -0.171 & -0.083 & 0.038 & -0.15 & -0.203 & -0.214 & 0.06 & -0.152 & -0.096 & 0.026 & 0.026 & -0.059 & $\begin{array}{l}0.328 \\
(* *)\end{array}$ & $\begin{array}{l}-0.294 \\
(*)\end{array}$ & $\begin{array}{c}-0.247 \\
(*)\end{array}$ & 1 & & & & & & & & & \\
\hline 18 P_cont & -0.009 & -0.195 & -0.028 & -0.284 & 0.031 & -0.159 & -0.204 & -0.224 & 0.13 & -0.188 & -0.122 & -0.072 & -0.076 & 0.573 & -0.388 & $\begin{array}{c}\text { (1) } \\
-0.416 \\
(* *)\end{array}$ & 0.740 & 0.740 & & & & & & & & & \\
\hline 20 P_pad & 0.158 & 0.084 & 0.05 & -0.065 & $\begin{array}{c}0.353 \\
(* *)\end{array}$ & -0.228 & -0.16 & -0.018 & 0.225 & 0.067 & 0.062 & -0.051 & -0.211 & $\begin{array}{c}0.347 \\
(* *)\end{array}$ & -0.183 & -0.277 & 0.499 & 0.09 & $\begin{array}{c}0.742 \\
(* *)\end{array}$ & 1 & & & & & & & \\
\hline 21 P_las & -0.144 & 0.027 & -0.111 & $\underset{(* *)}{-0.335}$ & 0.136 & $\begin{array}{l}-0.384 \\
(* *)\end{array}$ & $\begin{array}{c}-0.389 \\
(* *)\end{array}$ & -0.159 & 0.1 & -0.073 & -0.15 & -0.174 & -0.218 & 0.205 & -0.108 & $\begin{array}{l}-0.156 \\
-17\end{array}$ & $\begin{array}{l}0.466 \\
(* *)\end{array}$ & 0 & $\begin{array}{l}0.515 \\
(* *)\end{array}$ & $\begin{array}{l}0.557 \\
(* * *)\end{array}$ & 1 & & & & & & \\
\hline $22 \mathrm{P}_{-}^{\text {fut }}$ & 0.097 & 0.09 & 0.053 & $\begin{array}{c}-0.280 \\
(*)\end{array}$ & 0.225 & $\begin{array}{c}-0.410 \\
(* *)\end{array}$ & $\begin{array}{c}-0.447 \\
(* *)\end{array}$ & -0.096 & 0.129 & -0.059 & -0.069 & $\begin{array}{l}-0.262 \\
(*)\end{array}$ & -0.22 & 0.106 & -0.134 & -0.215 & 0.074 & 0.202 & $\begin{array}{l}0.492 \\
(* *)\end{array}$ & $\frac{\substack{0.350 \\
(* *)}}{(20)}$ & $\left.0.483^{* *}\right)$ & 1 & & & & & \\
\hline 23 Ai_pr & 0.204 & $\begin{array}{l}0.335 \\
(* *)\end{array}$ & 0.202 & 0.104 & 0.083 & -0.009 & $\begin{array}{c}0.234 \\
\left(^{*}\right)\end{array}$ & $\frac{0.326}{(* *)}$ & 0.119 & 0.082 & 0.085 & 0.094 & 0.041 & $\begin{array}{l}-0.288 \\
(* *)\end{array}$ & $\begin{array}{l}0.437 \\
(* * *)\end{array}$ & $\begin{array}{l}0.329 \\
(* *)\end{array}$ & $-\underset{(*)}{-0.264}$ & 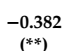 & 0.053 & -0.021 & 0.08 & 0.207 & 1 & & & & \\
\hline $24 \mathrm{Ctc}$ & 0.149 & $0.273\left({ }^{*}\right)$ & 0.206 & 0.172 & 0.061 & 0.006 & 0.115 & 0.239 & $\begin{array}{c}0.322 \\
(* *)\end{array}$ & 0.097 & 0.215 & 0.035 & $\begin{array}{c}0.230 \\
\left.{ }^{*}\right)\end{array}$ & 0.096 & 0.326 & $\begin{array}{l}0.399 \\
(* *)\end{array}$ & 0.115 & 0.007 & 0.127 & 0.206 & 0.213 & 0.175 & $0.377^{(* *)}$ & 1 & & & \\
\hline 25 Ito_r & -0.031 & -0.036 & -0.094 & -0.248 & -0.042 & -0.088 & -0.103 & -0.208 & -0.137 & $\begin{array}{c}-0.335 \\
(* *)\end{array}$ & 0.014 & -0.105 & -0.133 & 0.205 & 0.084 & 0.049 & 0.173 & 0.215 & 0.193 & 0.115 & $\left.0.334^{* *}\right)$ & 0.224 & 0.234 & 0.072 & 1 & & \\
\hline 26 Ito_o & -0.192 & -0.129 & $\begin{array}{c}-0.293 \\
(*)\end{array}$ & 0.247 & -0.007 & -0.203 & -0.188 & -0.168 & 0.062 & -0.186 & -0.148 & -0.123 & -0.241 & 0.13 & 0.088 & 0.039 & $\begin{array}{c}0.302 \\
\left.{ }^{*}\right)\end{array}$ & 0.22 & 0.231 & 0.137 & $\left.0.4799^{* *}\right)$ & 0.234 & 0.067 & 0.172 & $\begin{array}{c}0.520 \\
(* *)\end{array}$ & 1 & \\
\hline 27 Ito_p & 0.176 & 0.141 & 0.216 & -0.029 & $\begin{array}{c}0.372 \\
(* *)\end{array}$ & -0.013 & -0.044 & 0.208 & 0.213 & 0.162 & 0.106 & -0.131 & -0.136 & -0.199 & -0.066 & -0.086 & 0.004 & -0.034 & 0.09 & 0.136 & 0.134 & $\begin{array}{c}0.390 \\
(* *)\end{array}$ & $\begin{array}{c}0.302 \\
(*)\end{array}$ & -0.039 & 0.245 & 0.145 & 1 \\
\hline
\end{tabular}

$1 \mathrm{Au}=$ Task autonomy; $2 \mathrm{Var}=$ Variety of task; $3 \mathrm{Id}$ = Identity of task; 4 Sod=Working satisfaction; 5 Qual = Quality of assistance; $6 \mathrm{Ad}=$ Suitability of assistance; 7 Col = Collaboration between doctors and nurses; $8 \mathrm{C}_{-}$af $=$Emotional commitment; $9 \mathrm{C} \_\mathrm{co}=$ consecutive commitment; $10 \mathrm{C}_{-}$no $=$Normative commitment; 11 Su_o $=$ Perceived organizational support; 12 Su_c $=$ Support of the coordinator towards the change; $13 \mathrm{Com}=$ Quality of communication; $14 \mathrm{Ins}=$ Working uncertainty; 15 A_ind = Expectations of result related to individual benefits; 16 A_org = Expectations of result related to organizational benefits; $17 \mathrm{P} \_c a p=$ Concerns as to the individual capacity to cope with the change; $18 \mathrm{P}_{\text {_c cont }}=$ Concerns as to the content of change; $19 \mathrm{P} \_$mod $=$Concerns as to the change management modalities adopted; $20 \mathrm{P} \_$pad $=$Concerns as to handling the change; $21 \mathrm{P}_{-}$las = Concerns as to being left alone during the change; $22 \mathrm{P} \_$fut $=$Concerns for the future; 23 Ai_pr = Practical help; $24 \mathrm{Ctc}=$ Commitment to change; 25 Ito_r $=$ Intention of turnover inside the ward; 26 Ito_o $=$ Intention of turnover inside the organization; 27 Ito_p $=$ Intention of professional turnover.

$\left(^{*}\right)$ All the correlations are consistent for $p<0.05$; ${ }^{(*)}$ All the correlations are consistent for $p<0.01$ 
Table A4. Correlations between the variables studied at T2 (source: authors' elaboration).

\begin{tabular}{|c|c|c|c|c|c|c|c|c|c|c|}
\hline 1 & & 2 & 3 & 4 & 5 & 6 & 7 & 8 & 9 & 10 \\
\hline 1 Qual & 1 & & & & & & & & & \\
\hline $2 \mathrm{Ad}$ & $0.590(* *)$ & 1 & & & & & & & & \\
\hline $3 \mathrm{Col}$ & $0.4788^{(* *)}$ & $0.450(* *)$ & 1 & & & & & & & \\
\hline 4 Comp_gen & 0.119 & $-0.015,336{ }^{(*)}$ & & 1 & & & & & & \\
\hline 5 Comp_pro_rea & 0.201 & $0.075,383\left(^{* *}\right)$ & & $0.866^{(* *)}$ & 1 & & & & & \\
\hline 6 Proat_ind & $0.281\left(^{*}\right)$ & $0.136,319\left(^{*}\right)$ & & $0.620(* *)$ & $\left.0.5844^{* *}\right)$ & 1 & & & & \\
\hline 7 Proat_gru_org & 0.093 & $0.092,303\left(^{*}\right)$ & & $0.713(* *)$ & $0.757(* *)$ & $0.7099^{(*)}$ & 1 & & & \\
\hline 8 Ito $\mathrm{r}$ & 0.187 & 0.204 & 0.095 & 0.038 & 0.002 & 0.206 & 0.17 & 1 & & \\
\hline 9 Ito_o & -0.06 & 0.072 & -0.025 & $-0.317\left(^{*}\right)$ & -0.249 & -0.095 & -0.1050 .500 (**) $^{*}$ & & 1 & \\
\hline 10 Ito_p & -0.054 & -0.096 & -0.213 & $-0.309\left(^{*}\right)$ & -0.27 & -0.138 & $-0.0980 .419\left(^{* *}\right)$ & $0.693\left(^{(* *)}\right.$ & & 1 \\
\hline
\end{tabular}

1 Qual = Quality of assistance; $2 \mathrm{Ad}=$ Suitability of assistance; $3 \mathrm{Col}=$ Collaboration between doctors and nurses; 4 Comp_gen = Generation of ideas; 5 Comp_pro_rea = Promotion and Realization of ideas; 6 Proat_ind $=$ Proactivity at individual level; 7 Proat_gru_org $=$ Proactivity at group and organization level; 8 Ito_ $r=$ Intention of turnover inside the ward; 9 Ito_o $=$ Intention of turnover inside the organization; 10 Ito_p $=$ Intention of professional turnover. $\left(^{*}\right)$ All the correlations are consistent for $p<0.05$; $(* *)$ All the correlations are consistent for $p<0.01$. 


\section{References}

1. Armenakis, A.A.; Bedeian, A.G. Organizational Change: A Review of Theory and Research in the 1990s. J. Manag. 1999, 25, 293-315. [CrossRef]

2. Vakola, M.; Nikolaou, I. Attitudes towards Organizational Change: What Is the Role of Employees Stress and Commitment? Empl. Relat. 2005, 27, 160-174. [CrossRef]

3. Gordon, H.B.; O'Farrell, S.; Collier, M.; Dix, M.; Rotstayn, L. The CSIRO Mk3. 5 Climate Model. Cawcr Tech. Rep. 2010, 21, 74 .

4. Cummings, G.G.; MacGregor, T.; Davey, M.; Lee, H.; Wong, C.A.; Lo, E.; Muise, M.; Stafford, E. Leadership styles and outcome patterns for the nursing workforce and work environment: A systematic review. Int. J. Nurs. Stud. 2010, 1547, 23. [CrossRef]

5. Bonacci, I.; Cicellin, M.V.; Galdiero, C.; Tamburis, O. 'Smart' healthcare organizations. An analysis of the organizational climate in a Paediatrics Department". In Proceedings of the 8th Edition of the International Forum on Knowledge Asset Dynamics (IFKAD) "Smart Growth: Organizations, Cities and Communities", Zagreb, Croatia, 12-14 June 2013.

6. Martin, A.J.; Jones, E.S.; Callan, V.J. The role of psychological climate in facilitating employee adjustment during organizational change in European. J. Work Organ. Psychol. 2005, 14, 263-283. [CrossRef]

7. Lewin, K. Teoria e Sperimentazione in Psicologia Sociale; Il Mulino: Bologna, Italy, 1951.

8. Baskerville, R.L.; Wood-Harper, A.T. A critical perspective on action research as a method for information systems research in Methods. J. Inf. Technol. 1996, 11, 235-246. [CrossRef]

9. Elsey, H.; Lathlean, J. Using action research to stimulate organizational change within health services: Experiences from two community based studies. Educ. Action Res. 2006, 14, 171-186. [CrossRef]

10. Hampshire, S. Justice Is Conflict; Princeton University Press: London, UK, 2000.

11. Moran, E.T.; Volkwein, J.F. The Cultural Approach to the Formation of Organizational Climate. Hum. Relat. 1992, 45, 19-47. [CrossRef]

12. Lewin, K.; Lippitt, R.; White, R.K. Patterns of Aggressive Behavior in Experimentally Created "Social Climates". J. Soc. Psychol. 1939, 10, 271-299. [CrossRef]

13. Forehand, G.A.; Von Haller, G. Environmental variation in studies of organizational behavior. Psychol. Bull. 1964, 62, 361-382. [CrossRef]

14. Campbell, J.P.; Dunette, M.D.; Lawler, E.E.; Weick, K.E. Managerial Behavior, Performance, and Effectiveness; McGraw-Hill Book Company: New York, NY, USA, 1970.

15. Deci, E.L.; Connell, J.P.; Ryan, R.M. Self-Determination in a Work Organization. J. Appl. Psychol. 1989, 74, 580-590. [CrossRef]

16. Gray-Toft, P.; Anderson, J.G. Stress among hospital nursing staff: Its causes and effects. Soc. Sci. Med. 1981, 15, 639-647. [CrossRef]

17. Terry, D.J.; Jimmieson, N.L. A stress and coping approach to organisational change: Evidence from three field studies. Aust. Psychol. 2003, 38, 92-101. [CrossRef]

18. Katona, C.; Lewis, G.; Malizia, A. Evidence-based guidelines for treating depressive disorders with antidepressants: A revision of the 2008 British Association for Psychopharmacology guidelines. J. Psychopharmacol. 2015, 29, 459-525.

19. Quaglino, G.P.; Mander, M. I Climi Organizzativi; Il Mulino: Bologna, Italy, 1987.

20. Pousetteab, A.; Larsmana, P.; Eklöfb, M.; Törnera, M. The relationship between patient safety climate and occupational safety climate in healthcare - A multi-level investigation. J. Saf. Res. Vol. 2017, 61, 187-198. [CrossRef]

21. Olsen, E.; Bjaalid, G.; Mikkelsen, A. Work climate and the mediating role of workplace bullying related to job performance, job satisfaction, and work ability: A study among hospital nurses. JAN Lead. Glob. Nurs. Res. 2017, 73, 2709-2719. [CrossRef]

22. Weng, S.; Kim, S.H.; Wu, C.L. Underlying influence of perception of management leadership on patient safety climate in healthcare organizations-A mediation analysis approach. Int. J. Qual. Health Care 2017, 29, 111-116. [CrossRef]

23. Garzi, R.; Giacomelli, G.; Vainieri, M. Soddisfazione sul lavoro e anzianità di servizio. In Spunti di Riflessione da Un'analisi Comparata in Diversi Contesti Organizzativi; Sicurezza e Scienze Sociali Editore Franco Angeli: Milano, Italy, 2018. 
24. Mansour, S.; Tremblay, D.G. How can we decrease burnout and safety workaround behaviors in health care organizations? The role of psychosocial safety climate. Pers. Rev. 2019, 48, 528-550. [CrossRef]

25. Salas, R.N.; Jha-B, A.K. Climate change threatens the achievement of effective universal healthcare. $B M J$ 2019, 366, 302. [CrossRef]

26. Vainieri, M.; Ferre, F.; Giacomelli, G. Explaining performance in health care: How and when top management competencies make the difference. Health Care Manag. 2019, 44, 306-317. [CrossRef]

27. Shilt-Moody, N.; Tsai, E. Turning the tide: The shift to climate change mitigation. J. Healthc. Risk 2019, 39, 36-41. [CrossRef] [PubMed]

28. Wellbery, C. Climate Change Health Impacts: A Role for the Family Physician. Am. Fam. Physician 2019, 100, 602-603. [PubMed]

29. Sönmez, B.; Yıldırım, A. The mediating role of autonomy in the effect of pro-innovation climate and supervisor supportiveness on innovative behavior of nurses. Eur. J. Innov. Manag. 2019, 22, 41-58. [CrossRef]

30. Jiang, L.; Lavaysse, L.M.; Probst, T.M. Safety climate and safety outcomes: A meta-analytic comparison of universal vs. industry-specific safety climate predictive validity. Work Stress 2019, 33, 41-57. [CrossRef]

31. Ciancaleoni, G.; Santi, C.; Ragni, M.; Braga, A.L. Charge-displacement analysis as a tool to study chalcogen bonded adducts and predict their association constants in solution. Dalton Trans. 2015, 46, 20168-20175. [CrossRef]

32. Benito, G.; Macklin, M.G.; Zielhofer, C.; Jones, A.F. Holocene flooding and climate change in the Mediterranean. Catena 2015, 130, 13-33. [CrossRef]

33. Huselid, M.A. The Impact of Human Resource Management Practices on Turnover, Productivity, and Corporate Financial Performance. Acad. Manag. J. 1995, 38, 635-672.

34. Morgeson, F.P.; Humphrey, S.E. The Work Design Questionnaire (WDQ): Developing and validating a comprehensive measure for assessing job design and the nature of work. J. Appl. Psychol. 2006, 91, 1321-1339. [CrossRef]

35. Lingard, L.; Levinson, W. Grounded theory, mixed methods, and action research. Br. Med. J. 2008, 337 , a567. [CrossRef]

36. McTaggart, R.; Kemmis, S. The Action Research Planner; Deakin University Press: Geelong, Australia, 1982.

37. Donnellan, B. IT systems to support innovation. In IT Innovation for Adaptability and Competitiveness; Fitzgerald, B., Wynn, E., Eds.; Kluwer Academic Publishers: Boston, MA, USA, 2004.

38. Avallone, F.; Bonaretti, M. Benessere Organizzativo. Per Migliorare la Qualità del Lavoro Nelle Amministrazioni Pubbliche; Rubbettino Editore: Soveria Mannelli, Italy, 2003.

39. Wienand, U.; Cinotti, R.; Nicoli, A.; Bisagni, M. Evaluating the organisational climate in Italian public healthcare institutions by means of a questionnaire. BMC Health Serv. Res. 2007, 7, 73. [CrossRef]

40. Imai, K.; Keele, L.; Tingley, D. A general approach to causal mediation analysis. Psychol. Methods 2010, 15, 309-334. [CrossRef]

41. Hayes, A.F. Introduction to Mediation, Moderation, and Conditional Process Analysis A Regression-Based Approach; Guilford Publications: New York, NY, USA, 2013.

42. Litwin, G.H.; Stringer, R.A. Motivation and Organizational Climate; Harvard Business School Press: Cambridge, MA, USA, 1968.

43. Formisano, V. Analisi del clima organizzativo: Il caso di un istituto di credito. Riv. Banc. Minerva Banc. 2009, 65, 1-2.

44. Dorz, S.; Novara, C.; Sica, C.; Sanavio, E. La sindrome del burnout in operatori sanitari a contatto con malati di AIDS: Variabili predittive. G. Ital. Di Med. Lav. Ergon. 2004, 26, 114-118.

45. Cohen, J.; Cohen, P.; West, S.G.; Aiken, L.S. Applied Multiple Regression/Correlation Analysis for the Behavioural Sciences; Lawrence Erlbaum Associates: Mahwah, NJ, USA, 2003.

46. Bascle, G. Controlling for endogeneity with instrumental variables in strategic management research. Strateg. Organ. 2008, 6, 285-327. [CrossRef]

47. Tchetgen, T.; Chetgen, E.J.; Walter, S.; Vansteelandt, S.; Martinussen, T.; Glymour, M. Instrumental variable estimation in a survival context. Epidemiology 2015, 26, 402-410. [CrossRef]

48. Lynch, S.M.; Brown, J.S. Stratification and Inequality over the life course. In Handbook of Aging and the Social Sciences, 7th ed.; Bintstock, R.H., George, L.K., Eds.; Academic Press: New York, NY, USA, 2011; pp. $105-117$. 
49. Snow, C. Reading for understanding: Toward an R\&D program in reading comprehension. Read. Underst. Rand Corp. 2002, 42, 1-34.

50. Greenhalgh, T.; Robert, G.; Macfarlane, F.; Bate, P.; Kyriakidou, O.; Peacock, R. Storylines of research in diffusion of innovation: A meta-narrative approach to systematic review. Soc. Sci. Med. 2005, 61, 417-430. [CrossRef]

51. Crant, J.M. The proactive personality scale and objective job performance among reale state agents. J. Appl. Psychol. 1995, 80, 532-537. [CrossRef]

52. Odoardi, C.; Colaianni, G.; Battistelli, A.; Picci, P. The influence of organizational characteristics on the expectations before an innovation. Risorsa Uomo 2008, 14, 76-90.

53. Wayne, S.J.; Shore, L.M.; Liden, R.C. Perceived Organizational Support and Leader-Member Exchange: A Social Exchange Perspective. Acad. Manag. J. 1997, 40, 82-111.

54. Gerstner, C.R.; Day, D.V. Meta-Analytic Review of Leader-Member Exchange Theory: Correlates and Construct. J. Appl. Psychol. 1997, 82, 827-844. [CrossRef]

55. Judge, T.A.; Colbert, A.E.; Ilies, R. Intelligence and leadership: A quantitative review and test of theoretical propositions. J. Appl. Psychol. 2004, 89, 542-552. [CrossRef]

56. Invernizzi, E. La Comunicazione Organizzativa: Teorie, Modelli e Metodi; Giuffrè: Milan, Italy, 2000.

57. Amabile, T.M. A model of creativity and innovation in organizations. In Research in Organization Behavior; Staw, B.M., Cummings, L.L., Eds.; JAI Press: Greenwich, CT, USA, 1988; pp. 187-209.

58. Mumford, M.D.; Hunter, S.T. Innovation in organizations: A multi-level perspective on creativity. In Research in Multi-Level; Yammarino, F.J., Dansereau, F., Eds.; Elsevier: Oxford, UK, 2005; Volume 4, pp. 11-74.

59. Wanberg, C.R.; Banas, J.T. Predictors and outcomes of openness to changes in a reorganizing workplace. J. Appl. Psychol. 2000, 85, 132-142. [CrossRef] [PubMed]

60. Kreitner, R.; Kinicki, A. Comportamento Organizzativo; Apogeo: Milan, Italy, 2008.

61. Picci, P.; Battistelli, A. La ricerca psicosociale sull'innovazione al lavoro tra fattori antecedenti e dinamiche di processo. G. Ital. Di Psicol. 2010, 2, 341-366.

62. Amabile, T.M.; Conti, R.; Coon, H.; Lazenby, J.; Herron, M. Assessing the work environment for creativity. J. Acad. Manag. 1996, 39, 1154-1184.

63. Brown, S.L.; Eisenhardt, K.M. The Art of Continuous Change: Linking Complexity Theory and Time-Paced Evolution. Relentlessly Shifting Organ. Adm. Sci. Q. 1997, 42, 1-34. [CrossRef]

64. Bateman, T.S.; Crant, J.M. The proactive component of organizational behavior: A measure and correlates. J. Organ. Behav. 1993, 14, 103-118. [CrossRef]

65. Dong, W.; Wang, Z.; Josephson, W.; Charikar, M.; Li, K. Modeling LSH for Performance Tuning. In Proceedings of the 17th ACM Conference on Information and Knowledge Management, Napa Valley, CA, USA, 26-30 October 2008.

66. Loehlin, J.C. Genes and Environment in Personality Development. Eur. J. Personal. 1993, 7, 209-210.

67. West, M.A.; Farr, J.L. Innovation at work. In Innovation and Creativity at Work; West, M.A., Farr, J.L., Eds.; Wiley: Chichester, UK, 1990; pp. 1-13.

68. Ryan, A.; Schmit, M.J.; Johnson, R. Attitudes and effectiveness: Examining relations at an organizational level. Pers. Psychol. 1996, 49, 853-882. [CrossRef]

69. Koys, D.J. The effects of employee satisfaction, organizational citizenship behavior, and turnover on organizational effectiveness: A unit-level, longitudinal study. Pers. Psychol. 2001, 54, 101-114. [CrossRef]

70. Anderson, N.R.; West, M.A. Measuring climate for work group innovation: Development and validation of the team climate inventory. J. Organ. Behav. 1998, 19, 235-258. [CrossRef]

71. Maynard, A. Developing the health care market. Econ. J. 1991, 101, 1277-1286. [CrossRef]

72. Ferlie, E. The creation and evolution of quasi markets in the public sector: A problem for strategic management. Strateg. Manag. J. 1992, 13, 79-97. [CrossRef]

73. Kitchener, M.; Whipp, R. Tracks of change in hospitals: A study of quasi-market transformation. J. Manag. Med. 2013, 10, 47-61. [CrossRef]

74. Cohen, K.J.; Hawawini, G.A.; Maier, S.F.; Schwartz, R.A.; Whitcomb, D.K. Friction in the trading process and the estimation of systematic risk. J. Financ. Econ. 1983, 12, 263-278. [CrossRef] 
75. Duygulu, E.; Ozeren, E.; Işıldar, P.; Appolloni, A. The Link between Mission Statements and Performance: Formulating the Right Strategy for Small and Medium-Sized Enterprises (SMEs). Sustainability 2016, 8, 698. [CrossRef]

76. Binci, D.; Belisari, S.; Appolloni, A. BPM and change management: An ambidextrous perspective. Bus. Process Manag. J. 2019, 26, 1-23. [CrossRef] 